ARTICLE

\title{
Platinum single-atom catalyst coupled with transition metal/metal oxide heterostructure for accelerating alkaline hydrogen evolution reaction
}

Kai Ling Zhou ${ }^{1,2}$, Zelin Wang ${ }^{1,2}$, Chang Bao Han ${ }^{1 凶}$, Xiaoxing Ke ${ }^{1 凶}$, Changhao Wang (1) ${ }^{1}$, Yuhong Jin, Qianqian Zhang ${ }^{1}$, Jingbing Liu', Hao Wang ${ }^{1 凶}$ \& Hui Yan ${ }^{1}$

Single-atom catalysts provide an effective approach to reduce the amount of precious metals meanwhile maintain their catalytic activity. However, the sluggish activity of the catalysts for alkaline water dissociation has hampered advances in highly efficient hydrogen production. Herein, we develop a single-atom platinum immobilized $\mathrm{NiO} / \mathrm{Ni}$ heterostructure $\left(\mathrm{Pt}_{\mathrm{SA}}-\mathrm{NiO}\right.$ / $\mathrm{Ni}$ ) as an alkaline hydrogen evolution catalyst. It is found that Pt single atom coupled with $\mathrm{NiO} / \mathrm{Ni}$ heterostructure enables the tunable binding abilities of hydroxyl ions $\left(\mathrm{OH}^{\star}\right)$ and hydrogen $\left(H^{\star}\right)$, which efficiently tailors the water dissociation energy and promotes the $\mathrm{H}^{*}$ conversion for accelerating alkaline hydrogen evolution reaction. A further enhancement is achieved by constructing $\mathrm{Pt}_{\mathrm{SA}_{\mathrm{A}}}-\mathrm{NiO} / \mathrm{Ni}$ nanosheets on $\mathrm{Ag}$ nanowires to form a hierarchical three-dimensional morphology. Consequently, the fabricated $\mathrm{Pt}_{\mathrm{SA}}-\mathrm{NiO} / \mathrm{Ni}$ catalyst displays high alkaline hydrogen evolution performances with a quite high mass activity of $20.6 \mathrm{~A} \mathrm{mg}^{-1}$ for $\mathrm{Pt}$ at the overpotential of $100 \mathrm{mV}$, significantly outperforming the reported catalysts.

\footnotetext{
${ }^{1}$ Faculty of Materials and Manufacturing, Beijing University of Technology, Beijing, P. R. China. ${ }^{2}$ These authors contributed equally: Kai Ling Zhou, Zelin Wang.

凶email: cbhan@bjut.edu; kexiaoxing@bjut.edu.cn; haowang@bjut.edu.cn
} 
$\mathrm{H}$ ydrogen $\left(\mathrm{H}_{2}\right)$ has been regarded as the most promising energy carrier alternative to fossil fuels due to the environmental friendliness nature and high gravimetric energy density ${ }^{1,2}$. Electrocatalytic water splitting powered by wind energy or solar technologies for hydrogen generation is considered a sustainable strategy ${ }^{3}$. For an optimal electrocatalyst, minimizing the energy barrier and increasing the active sites are desirable for boosting the hydrogen evolution reaction (HER $)^{4-6}$. Despite the significant progress that has been presented in nonprecious catalysts ${ }^{7,8}$, the platinum $(\mathrm{Pt})$-based materials are still regarded as the most active catalysts for HER due to its optimal binding ability with hydrogen ${ }^{9-12}$. However, the high cost and scarcity of Pt hamper its large-scale application in electrolyzers for $\mathrm{H}_{2}$ production. Single-atom catalysts (SACs) provide an effective approach to reduce the amount of $\mathrm{Pt}$ meanwhile maintain its high intrinsic activity ${ }^{13-16}$. Recently, electrocatalytic HER in an alkaline condition has attracted more attention because catalyst systems are generally unstable in acidic media, resulting in safety and cost concerns in practice. Unfortunately, the alkaline HER activity of Pt-based catalysts is approximately two orders of magnitude lower than that in the acidic condition caused by the high activation energy of the water dissociation step $^{17-20}$. Alkaline HER process involves two electrochemical reaction steps: (step (i)) electron-coupled $\mathrm{H}_{2} \mathrm{O}$ dissociation to generate adsorbed hydrogen hydroxyl $\left(\mathrm{OH}^{*}\right)$ and hydrogen $\left(\mathrm{H}^{*}\right)$ (Volmer step), and (step (ii)) the concomitant interaction of dissociated $\mathrm{H}^{*}$ into molecular $\mathrm{H}_{2}$ (Heyrovsky or Tafel step) $)^{21,22}$. In particular, the additional energy in step (i) is required to overcome the barrier for splitting strong $\mathrm{OH}-\mathrm{H}$ bond, leading to a hamper of Pt SACs for alkaline HER application. Therefore, reducing the water dissociation energy in Volmer step (step (i)) for Pt SAC in alkaline media becomes vital for large-scale $\mathrm{H}_{2}$ production of industrialization.

Some strategies have been developed to improve Pt SACs HER activity. For instance, employing microenvironment engineering to immobilize single $\mathrm{Pt}$ atoms in MXene nanosheets $\left(\mathrm{Mo}_{2} \mathrm{TiC}_{2} \mathrm{~T}_{x}\right)$ and onion-like carbon nanospheres supports could greatly reduce the $H$ adsorption energy $\left(\Delta G_{\mathrm{H}}\right)$ and, thus, facilitates the release of $\mathrm{H}_{2}$ molecular ${ }^{23,24}$. Besides, $\mathrm{Pt}$ single atoms anchored alloy catalysts (Pt/np- $\left.\mathrm{Co}_{0.85} \mathrm{Se} \mathrm{SAC}\right)$ were constructed as an efficient HER electrocatalyst ${ }^{25}$, in which $\mathrm{np}-\mathrm{Co}_{0.85}$ Se can largely optimize the adsorption/desorption energy of hydrogen on atomic Pt sites, thus improving the HER kinetics. Furthermore, by utilizing the electronic interaction between the $\mathrm{Pt}$ atoms and the supports, single-atom Pt-anchored 2D $\mathrm{MoS}_{2}\left(\mathrm{Pt}_{\mathrm{SA}}-\mathrm{MoS}_{2}\right)^{26}$, nitrogendoped graphene nanosheets $\left(\mathrm{Pt}_{\mathrm{SA}}-\mathrm{NGNs}\right)^{27}$, and porous carbon matrix (Pt@PCM $)^{28}$ show enhanced electrocatalytic HER efficiency due to the higher $d$-band occupation near Fermi level, which can provide more free electrons for boosting the $\mathrm{H}^{*}$ conversion. Despite significant progress in Pt SACs, these methods are difficult to decrease the energy barrier of water dissociation in the Volmer step (step (i)). Generally, the $\mathrm{H}_{2} \mathrm{O}$ dissociation and $\mathrm{H}^{*}$ conversion happen on different catalytic sites $^{29}$. Especially, the HER activities of Pt-based catalysts in alkaline conditions are governed by the binding ability of hydroxyl species $\left(\mathrm{OH}^{*}\right)^{18,30,31}$, and the alkaline HER kinetics could be optimized by independently regulating the binding energy of reactants $\left(\mathrm{OH}\right.$ and $\mathrm{H}^{*}$ ) on dual active sites ${ }^{32-34}$. Inspired by these findings, the energy barrier of Pt SCAs for $\mathrm{H}_{2} \mathrm{O}$ dissociation in Volmer step (step (i)) in alkaline media could be decreased by incorporating or creating the dual active sites in the catalyst to independently modulate the binding energy of reactants $\left(\mathrm{OH}^{*}\right.$ and $\left.\mathrm{H}^{*}\right)$.

In this work, we developed a three-dimensional (3D) nanostructured electrocatalyst consisting of two-dimensional (2D) $\mathrm{NiO} / \mathrm{Ni}$ heterostructure nanosheets supported single-atom $\mathrm{Pt}$ attached on one-dimensional Ag nanowires (Ag NWs) conductive network $\left(\mathrm{Pt}_{\mathrm{SA}}-\mathrm{NiO} / \mathrm{Ni}\right)$. Density functional theory (DFT) calculations reveal that the dual active sites consisting of metallic $\mathrm{Ni}$ sites and $\mathrm{O}$ vacancies-modified $\mathrm{NiO}$ sites near the interfaces of $\mathrm{NiO} / \mathrm{Ni}$ heterostructure in $\mathrm{Pt}_{\mathrm{SA}}-\mathrm{NiO} / \mathrm{Ni}$ show the preferred adsorption affinity toward $\mathrm{OH}^{*}$ and $\mathrm{H}^{*}$, respectively, which efficiently facilitates water adsorption and reaching a barrier-free water dissociation step with a lower energy barrier of $0.31 \mathrm{eV}$ in Volmer step (step (i)) for $\mathrm{Pt}_{\mathrm{SA}}-\mathrm{NiO} / \mathrm{Ni}$ in the alkaline condition compared with that of $\mathrm{Pt}_{\mathrm{SA}}-\mathrm{Ni}(0.47 \mathrm{eV})$ and $\mathrm{Pt}_{\mathrm{SA}}-\mathrm{NiO}(1.42 \mathrm{eV})$ catalysts. In addition, anchoring Pt single atoms at the interfaces of $\mathrm{NiO} / \mathrm{Ni}$ heterostructure induces more free electrons on Pt sites due to the elevated occupation of the Pt $5 d$ orbital at Fermi level and the more suitable $\mathrm{H}$ binding energy $\left(\Delta G_{\mathrm{H}^{*}},-0.07 \mathrm{eV}\right)$ than that of $\mathrm{Pt}$ atoms at the $\mathrm{NiO}\left(\Delta G_{\mathrm{H}^{*}}, 0.74 \mathrm{eV}\right)$ and $\mathrm{Ni}\left(\Delta G_{\mathrm{H}^{*}}\right.$, $-0.38 \mathrm{eV}$ ), which efficiently promotes the $\mathrm{H}^{*}$ conversion and $\mathrm{H}_{2}$ desorption, thus accelerating overall alkaline HER (step (ii)). Furthermore, the Ag NWs-supported 3D morphology provides
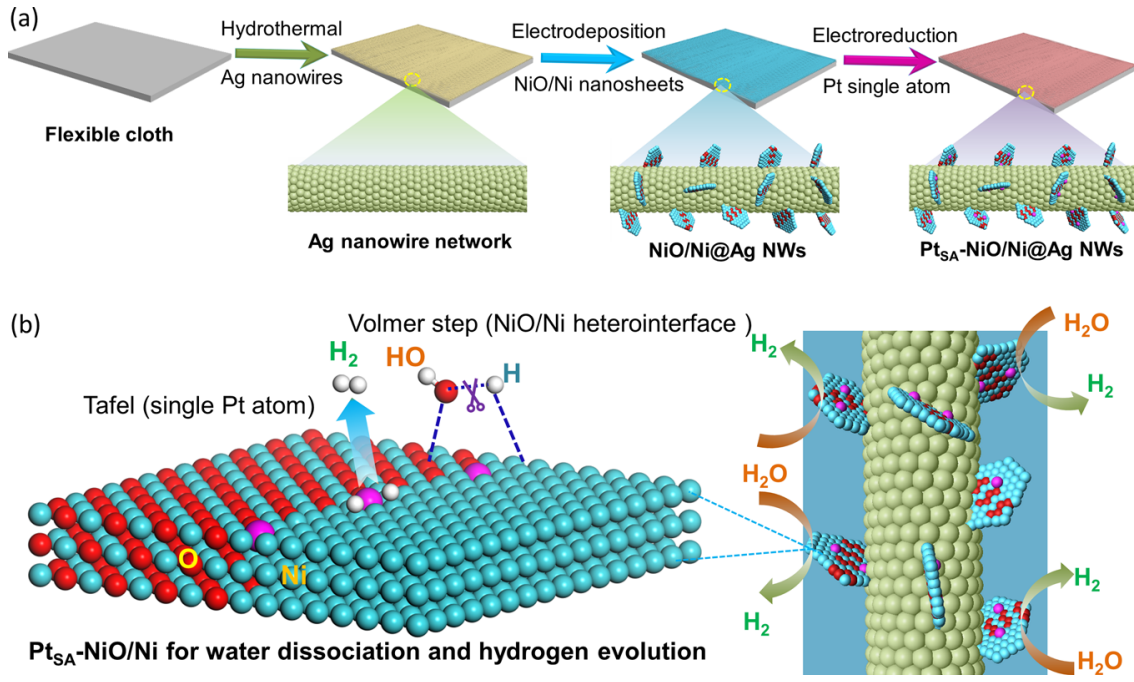

Fig. 1 Schematic illustration of synthesis and water splitting mechanism of $\mathbf{P t}_{\mathbf{S A}} \mathbf{- N i O} / \mathbf{N i}$. a The synthesis process of Pt single atom anchored $\mathrm{NiO} / \mathrm{Ni}$ heterostructure nanosheets on $\mathrm{Ag}$ nanowires network. b The mechanism of $\mathrm{Pt}_{\mathrm{SA}}-\mathrm{NiO} / \mathrm{Ni}$ network as an efficient catalyst toward large-scale water electrolysis in alkaline media. 
abundant active sites and accessible channels for charge transfer and mass transport. As a result, the fabricated $\mathrm{Pt}_{\mathrm{SA}}-\mathrm{NiO} / \mathrm{Ni}$ catalyst exhibits outstanding HER activity with a quite lower overpotential of $26 \mathrm{mV}$ at $10 \mathrm{~mA} \mathrm{~cm}^{-2}$ in $1-\mathrm{M} \mathrm{KOH}$. The mass activity of $\mathrm{Pt}_{\mathrm{SA}}-\mathrm{NiO} / \mathrm{Ni}$ is $20.6 \mathrm{~A} \mathrm{mg}^{-1} \mathrm{Pt}$ at the overpotential of $100 \mathrm{mV}$, which is 41 times greater than that of the commercial Pt/ $\mathrm{C}$ catalyst, significantly outperforming the reported catalysts. This work provides a design principle toward SAC systems for efficient alkaline HER.

\section{Results}

Synthesis and characterization of $\mathrm{Pt}_{\mathrm{SA}}-\mathrm{NiO} / \mathrm{Ni}$ catalyst. The fabrication process of $\mathrm{Pt}_{\mathrm{SA}}-\mathrm{NiO} / \mathrm{Ni}$ on $\mathrm{Ag} \mathrm{NWs}$ is illustrated in Fig. 1. In brief, the synthesized Ag NWs by a typical hydrothermal method ${ }^{35}$ were first loaded on the flexible cloth to form a conductive network. The loading of Ag NWs leads to a brown film deposited on the surface of the white cloth fabric substrate (Fig. S1a, b), and the loading capacity of Ag NWs was determined to be $\sim 0.47 \mathrm{mg} \mathrm{cm}^{-2}$. The surface of the cloth fabric was studied by scanning electron microscopy (SEM) as shown in Fig. S1d-f, and a large number of fibers is presented. The abundant interconnected pores consist of a rich number of seams in each fiber. After the loading of the Ag NWs, the cloth fabric fibers are covered, and the uniform Ag NWs layer forms on the surface of cloth fabric as shown in Fig. S1g-i. Then $\mathrm{Ni} / \mathrm{NiO}$ composite is attached to the Ag network by the facile electrodeposition process $^{36}$. In detail, the Ag NWs network-loaded cloth is immersed in nickel acetate aqueous solution followed by an electrochemical process with $-3.0 \mathrm{~V}$ versus SCE (saturated calomel electrode) for $200 \mathrm{~s}$ (Fig. S2), forming the uniformly distributed nanosheets on the Ag network (Fig. S3). Transmission electron microscopy (TEM, Fig. S4a, b) images, high-resolution TEM (HRTEM, Fig. S4c) image with corresponding fast Fourier transform (FFT pattern, Fig. S4d), and elemental mapping (Fig. S5) images clearly show that the metallic $\mathrm{Ni}$ is uniformly embedded in amorphous-like $\mathrm{NiO}$ nanosheets. Besides, the $\mathrm{X}$-ray diffraction (XRD, Fig. S6) pattern shows that only metallic Ni signal without distinctive peaks of $\mathrm{NiO}$ can be detected, and $\mathrm{X}$-ray photoelectron spectroscopy (XPS, Fig. S7) spectra suggest both metallic $\mathrm{Ni}$ and $\mathrm{Ni}$ oxide exists in $\mathrm{Ni} / \mathrm{NiO}$ sample, further confirming the composition of metallic $\mathrm{Ni}$ on $\mathrm{NiO}$. Interestingly, the deposited composition can be facilely controlled by performing various voltage in the nickel acetate aqueous solution ${ }^{36}$. Specifically, as above discussion, a high voltage of $-3 \mathrm{~V}$ versus SCE will generate the $\mathrm{Ni} / \mathrm{NiO}$ composite on $\mathrm{Ag} \mathrm{NWs}(\mathrm{NiO} / \mathrm{Ni})$, whereas a lower voltage of $-1 \mathrm{~V}$ versus SCE could prepare the pure $\mathrm{NiO}$ on Ag NWs (NiO, Figs. S8-10). Besides, the pure metallic Ni on Ag network (Ni, Figs. S11-14) was fabricated by a traditional electrodeposition method with $1.2 \mathrm{~V}$ for $200 \mathrm{~s}$ in a mix solution containing $0.10-\mathrm{M} \mathrm{NiCl}$ and $0.09-\mathrm{M} \mathrm{H}_{3} \mathrm{BO}_{3}$. Afterward, the single-atom $\mathrm{Pt}$-immobilized $\mathrm{NiO} / \mathrm{Ni}\left(\mathrm{Pt}_{\mathrm{SA}}-\mathrm{NiO} / \mathrm{Ni}\right)$ is obtained by sequentially electroreduction process with cyclic voltammetry in 1-M KOH solution containing low-concentration Pt metallic salts. Abundant voids and $\mathrm{O}$ vacancy defects at the surfaceexposed interfaces of $\mathrm{NiO} / \mathrm{Ni}$ heterostructure induced by crystallattice dislocation and phase transition ${ }^{37-39}$ will provide efficient sites for trapping $\mathrm{Pt}$ single atom. The electrodeposition of $\mathrm{Pt}_{\mathrm{SA}^{-}}$ $\mathrm{NiO} / \mathrm{Ni}$ leads to a black film deposited on the surface of $\mathrm{Ag}$ NWs@cloth fabric (Fig. S1b, c). In addition, the Ag NWs@cloth fabric supported $\mathrm{Pt}_{\mathrm{SA}}-\mathrm{NiO} / \mathrm{Ni}$ catalyst also shown high wettability (Fig. S15). The water dissociation of Volmer step in alkaline aqueous media is expected to be accelerated by $\mathrm{O}$ vacanciesmodified $\mathrm{NiO}$ near the interfaces interacted strongly with $\mathrm{OH}$ and metallic $\mathrm{Ni}$ interacted with $\mathrm{H}$ for $\mathrm{H}-\mathrm{OH}$ bond destabilization (step (i)). Apart from the Volmer step, $\mathrm{NiO} / \mathrm{Ni}$ heterostructure-supported single-atom Pt sites could show more suitable $\mathrm{H}$ binding ability for the conversion and deabsorption of dissociated $\mathrm{H}$ (step (ii)), further accelerating overall HER kinetics of $\mathrm{Pt}_{\mathrm{SA}}-\mathrm{NiO} / \mathrm{Ni}$ in an alkaline condition.

The phase evolution of samples is investigated by XRD pattern as shown in Fig. 2a, in which no Pt characteristic peaks are detected, implying the absence of $\mathrm{Pt}$ cluster and particles in $\mathrm{Pt}_{\mathrm{SA}^{-}}$ $\mathrm{NiO} / \mathrm{Ni}$. The SEM (Fig. 2b, c) images show the well-distributed and open $3 \mathrm{D}$ nanosheets morphology for $\mathrm{Pt}_{\mathrm{SA}}-\mathrm{NiO} / \mathrm{Ni}$. During the single-atom $\mathrm{Pt}$ electroreduction process, some quantities of hydrogen bubbles are generated and released due to the high cathodic potential between 0 and $-0.50 \mathrm{~V}$ versus reversible hydrogen electrode (RHE) in alkaline conditions ${ }^{40}$. In this case, the unchanged $\mathrm{Pt}_{\mathrm{SA}}-\mathrm{NiO} / \mathrm{Ni}$ nanosheets morphology on $\mathrm{Ag} \mathrm{NWs}$ compared with the original $\mathrm{NiO} / \mathrm{Ni}$ (Fig. S3) indicates the high structural stability of the catalyst for HER application, and the exposed $\mathrm{NiO} / \mathrm{Ni}$ nanosheet could also provide more sites for $\mathrm{Pt}$ atoms immobilization and improve the HER performance. The TEM (Fig. S16) images suggest that the nanosheets consist of few $\mathrm{NiO} / \mathrm{Ni}$ layers for $\mathrm{Pt}_{\mathrm{SA}}-\mathrm{NiO} / \mathrm{Ni}$. The high-angle annular darkfield STEM (HAADF-STEM, Fig. 2d) image displays bright spots along with the interfaces of $\mathrm{NiO} / \mathrm{Ni}$ heterostructure, corresponding to heavy constituent atoms species, which efficiently confirms the immobilization of atomically dispersed $\mathrm{Pt}$ atoms in the $\mathrm{NiO} /$ $\mathrm{Ni}$ nanosheets. The magnified HAADF-STEM image (Fig. 2e) suggests that the single $\mathrm{Pt}$ atoms are mostly immobilized at the interfaces of the $\mathrm{NiO} / \mathrm{Ni}$ heterostructure. Based on these findings, the atomic environment of $\mathrm{Pt}$ atom was explored via the DFToptimized structure (Figs. 2f, $g$ and S17), and the result suggests that the $\mathrm{Pt}$ atoms are fixed at the $\mathrm{Ni}$ positions by binding with $\mathrm{O}$ atom and $\mathrm{Ni}$ atoms near the interfaces of the $\mathrm{NiO} / \mathrm{Ni}$ heterostructure. Here, it needs to note that the theoretical prediction is limited due to the use of the crystalline $\mathrm{NiO}$ model instead of amorphous-like NiO during DFT calculation. Further, the HRTEM shows one distinct lattice fringes of $0.18 \mathrm{~nm}$, matching well with metallic $\mathrm{Ni}$ (200) crystallographic planes (Fig. 2h). The FFT pattern (inset in Fig. 2h) shows four distinct rings: the red ring corresponds to the metallic $\mathrm{Ni}$ (200) plane ${ }^{41}$, and the yellow rings with the highly diffused halo are assigned to the $\mathrm{NiO}$ phase $\mathrm{s}^{36,42}$. These results further confirm the formation of single-atom $\mathrm{Pt}$-anchored $\mathrm{NiO} / \mathrm{Ni}$ composition, and the interfacial coupling of $\mathrm{Pt}$ single atom with $\mathrm{NiO} / \mathrm{Ni}$ does not change the phase structure of $\mathrm{NiO} / \mathrm{Ni}$. Moreover, the elemental mapping, SEM image, and HAADF-STEM image (Figs. 2i-n and S18-20) show that $\mathrm{Pt}$ atoms are uniformly dispersed throughout $\mathrm{NiO} / \mathrm{Ni}$ nanosheets. Besides, as a comparison, $\mathrm{Pt}_{\mathrm{SA}^{-}}$ $\mathrm{NiO}$ and $\mathrm{Pt}_{\mathrm{SA}}-\mathrm{Ni}$ were fabricated under the same conditions as $\mathrm{Pt}_{\mathrm{SA}}-\mathrm{NiO} / \mathrm{Ni}$ but replacing $\mathrm{NiO} / \mathrm{Ni}$ with $\mathrm{NiO}$ and $\mathrm{Ni}$, respectively. The corresponding HAADF-STEM images (Fig. S21) confirm the atomically dispersed $\mathrm{Pt}$ in the $\mathrm{NiO}$ and metallic $\mathrm{Ni}$ phase.

The electronic state evolution of the single $\mathrm{Pt}$ atoms in $\mathrm{NiO} / \mathrm{Ni}$, $\mathrm{NiO}$, and Ni supports is explored by XPS as shown in Fig. 3a. The $\mathrm{Pt} 4 f$ spectrums of $\mathrm{Pt}_{\mathrm{SA}}-\mathrm{NiO} / \mathrm{Ni}, \mathrm{Pt}_{\mathrm{SA}}-\mathrm{NiO}$, and $\mathrm{Pt}_{\mathrm{SA}}-\mathrm{Ni}$ are close to $\mathrm{Pt}^{0}$ but show some positive shift with different extents compared with Pt foil, confirming the electrochemical reduction of $\mathrm{PtCl}_{6}{ }^{2-}$ and the electronic interaction by charge transfer from Pt sites to the supports $(\mathrm{NiO} / \mathrm{Ni}, \mathrm{NiO} \text {, and } \mathrm{Ni})^{43}$. Specifically, the $\mathrm{Pt}_{\mathrm{SA}}-\mathrm{NiO}$ shows the largest positive shift in $\mathrm{Pt} 4 f$ spectrum, suggesting the maximum electron loss of Pt species ${ }^{44,45}$. Besides, the fitting curve of Pt XPS spectrums display Pt(IV) species in the samples, which derives from the adsorbed $\mathrm{PtCl}_{6}{ }^{2-}$ ions on the surface of the sample ${ }^{46,47}$. Further, the electronic state and atomic environment of $\mathrm{Pt}$ atoms in $\mathrm{NiO} / \mathrm{Ni}, \mathrm{NiO}$, and $\mathrm{Ni}$ supports are further verified by performing X-ray absorption fine structure measurements. As shown in Fig. 3b, the evolutions of $\mathrm{Pt} L_{3}$-edge $\mathrm{X}$-ray absorption near edge structure (XANES) spectra with 

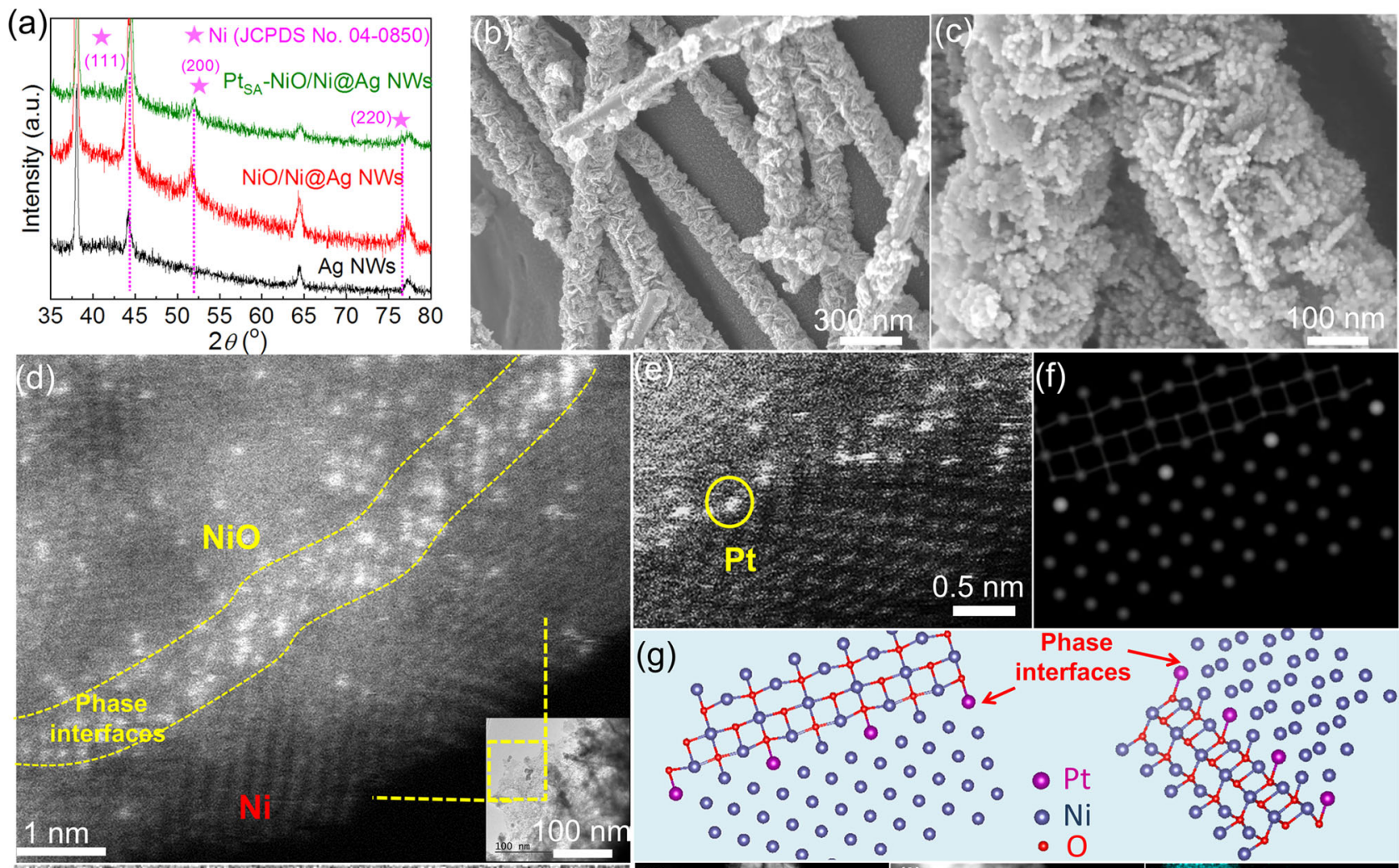

(g)
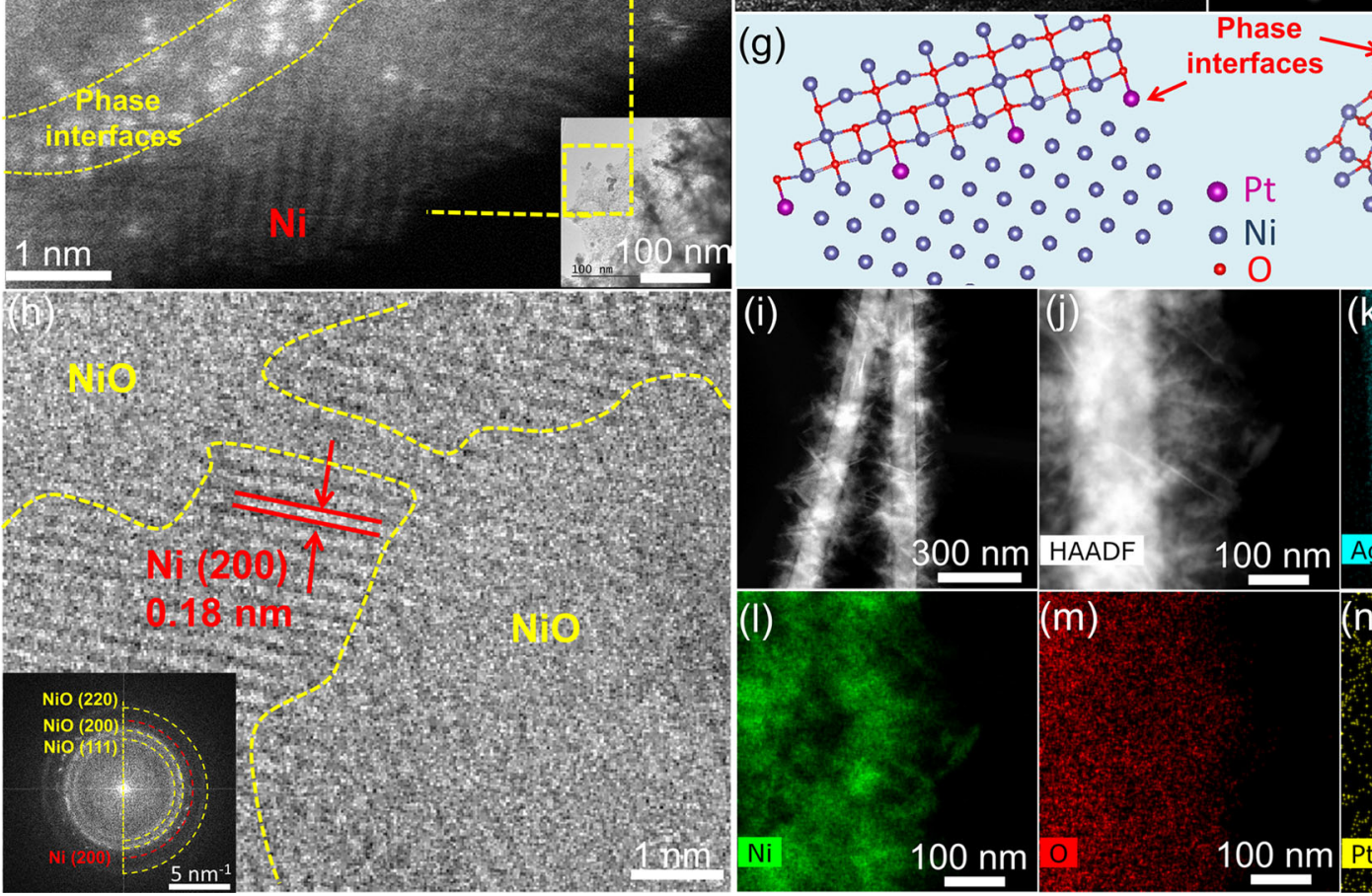

0.00000000
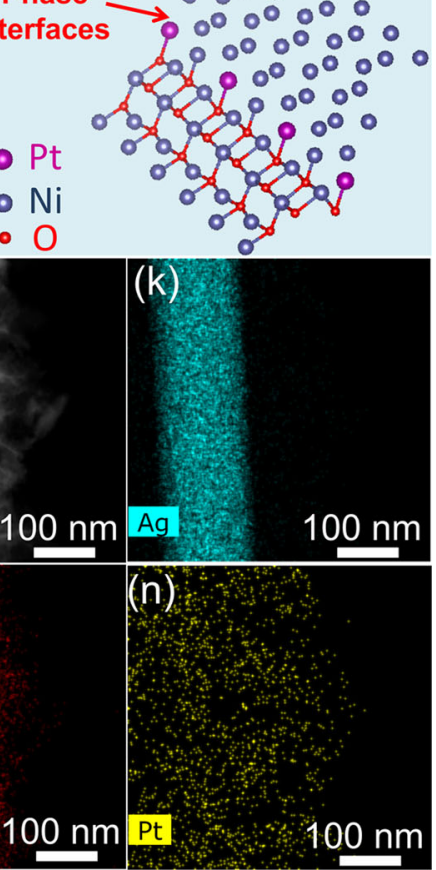

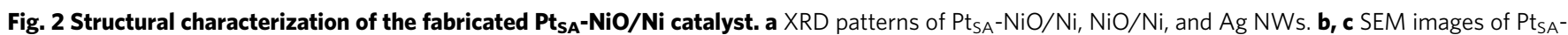
$\mathrm{NiO} / \mathrm{Ni}$. $\mathbf{d}$ HAADF-STEM image of $\mathrm{Pt}_{\mathrm{SA}}-\mathrm{NiO} / \mathrm{Ni}$. e Magnified HAADF-STEM image of $\mathrm{Pt}_{\mathrm{SA}}-\mathrm{NiO} / \mathrm{Ni}$ and $\mathbf{f}, \mathbf{g}$ the illustrated interface structure by DFT calculation, showing the atomically dispersed $\mathrm{Pt}$ atoms at Ni position (circles in (e)). $\mathbf{h} \mathrm{HRTEM}$ images of $\mathrm{Pt}_{\mathrm{SA}}-\mathrm{NiO} / \mathrm{Ni}$ and the insert in (h) show the related FFT pattern of $\mathrm{Pt}_{\mathrm{SA}}-\mathrm{NiO} / \mathrm{Ni}$. $\mathbf{i}, \mathbf{j}$ HAADF-STEM images of $\mathrm{Pt}_{\mathrm{SA}}-\mathrm{NiO} / \mathrm{Ni}$ at different magnifications and $\mathbf{k}-\mathbf{n}$ the elemental mapping of the corresponding elementals.

different supports are distinguished, in which the intensity of white-line peaks corresponds to the transfer of the Pt $2 p_{3 / 2}$ coreelectron to $5 d$ states, and thus is used as an indicator of Pt $5 d$ band occupancy ${ }^{27,48}$. The overall white-line intensity gradually decreases as the change of support from $\mathrm{NiO}, \mathrm{NiO} / \mathrm{Ni}$ to metallic $\mathrm{Ni}$, corresponding to the increase of $5 d$ occupancy of Pt. Hence, higher $5 d$ occupancy indicates the less charge loss of the singleatom Pt after coordinating with the supports, which is consistent with the results of XPS analysis in Fig. 3a.

To quantitate the structural information of the electronic state, the white-line peak evolution of Pt can be clearly described by the differential XANES spectra ( $\triangle$ XANES, Fig. S22) by subtracting the spectra from that of $\mathrm{Pt}$ foil. The valence state of $\mathrm{Pt}$ can be quantitatively examined by the integration of the white-line peak in $\triangle$ XANES spectra. As shown in Fig. 3c, the average valence state of Pt increase from $+0.29,+0.73$, to +1.23 for the $\mathrm{Pt}_{\mathrm{SA}}-\mathrm{Ni}, \mathrm{Pt}_{\mathrm{SA}}-\mathrm{NiO} /$ $\mathrm{Ni}$, and $\mathrm{Pt}_{\mathrm{SA}_{\mathrm{A}}}-\mathrm{NiO}$ catalysts, respectively. The evolution of the atomic coordination configuration of $\mathrm{Pt}$ was further revealed by extended X-ray absorption fine structure spectroscopy (EXAFS, Fig. 3d), in which the typical Pt-Pt contribution peak of Pt foil at about $2.7 \AA$ is absent for the fabricated $\mathrm{Pt}_{\mathrm{SA}_{\mathrm{A}}}-\mathrm{NiO} / \mathrm{Ni}, \mathrm{Pt}_{\mathrm{SA}}-\mathrm{NiO}$, and $\mathrm{Pt}_{\mathrm{SA}}-\mathrm{Ni}$ catalysts, strongly confirming the single $\mathrm{Pt}$ atoms dispersion. Further, the first-shell EXAFS fitting of $\mathrm{Pt}_{\mathrm{SA}}-\mathrm{NiO} / \mathrm{Ni}$ sample (Fig. 3e and Table S1) gives a coordination number $(\mathrm{CN})$ of 1.3 for Pt-O contribution and 5.8 for Pt-Ni contribution. For $\mathrm{Pt}_{\mathrm{SA}}{ }^{-}$ $\mathrm{NiO}$, the fitting results of EXAFS spectra suggested $\mathrm{CN}$ about 2.4 for Pt-O contributions and 2.1 for $\mathrm{CN}$ for $\mathrm{Pt}-\mathrm{Ni}$ contributions. Whereas Pt-Ni contribution with 4.9 for $\mathrm{CN}$ and no Pt-O 

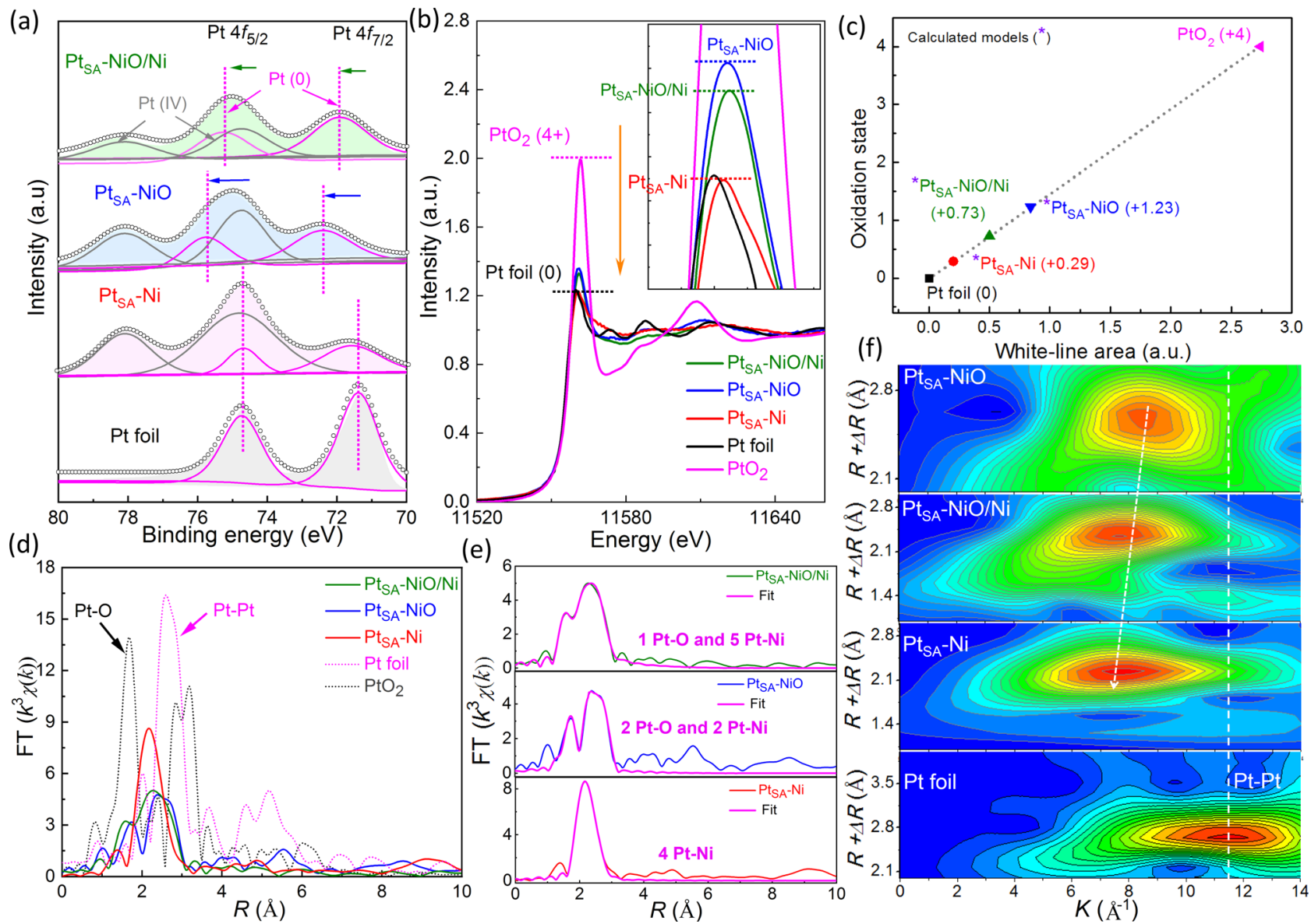

Fig. 3 Electronic state and atomic structure characterization. a Pt $4 f$ spectra, $\mathbf{b}$ XANES spectra, and $\mathbf{c}$ calculated Pt oxidation states derived from $\triangle X A N E S$ spectra of $\mathrm{Pt}_{\mathrm{SA}}-\mathrm{NiO} / \mathrm{Ni}, \mathrm{Pt}_{\mathrm{SA}}-\mathrm{NiO}$, and $\mathrm{Pt}_{\mathrm{SA}}-\mathrm{Ni}$, and $\mathrm{Pt}$ foil is given as a reference. $\mathbf{d}$ Corresponding FT-EXAFS curves of Fig. $3 \mathrm{~b}$. e EXAFS fitting curve of $\mathrm{Pt}_{\mathrm{SA}}-\mathrm{NiO} / \mathrm{Ni}, \mathrm{Pt}_{\mathrm{SA}}-\mathrm{NiO}$, and $\mathrm{Pt}_{\mathrm{SA}}-\mathrm{Ni}$-space. $\mathbf{f}$ EXAFS wavelet transform plots of $\mathrm{Pt}_{\mathrm{SA}}-\mathrm{NiO} / \mathrm{Ni}, \mathrm{Pt}_{\mathrm{SA}}-\mathrm{NiO}, \mathrm{Pt}_{\mathrm{SA}}-\mathrm{Ni}$, and $\mathrm{Pt}$ foil.

contributions are found in the fitting of $\mathrm{Pt}_{\mathrm{SA}}$-Ni EXAFS spectra. Combining the DFT-optimized structure (Fig. S23), the Pt atoms are mainly immobilized at the interfacial $\mathrm{Ni}$ positions by coordinating with one $\mathrm{O}$ atom and five $\mathrm{Ni}$ atoms in $\mathrm{Pt}_{\mathrm{SA}}-\mathrm{NiO} / \mathrm{Ni}$, which is consistent with the conclusion of HAADF-STEM analysis (Fig. $2 \mathrm{~d}-\mathrm{g}$ ). To more precisely clarify the atomic dispersion and coordination conditions of $\mathrm{Pt}$, the wavelet transform analysis was carried out due to its more efficient resolution ability in $K$ spaces and radial distance ${ }^{49,50}$, in which the atoms at similar coordination conditions and distances could be discriminated ${ }^{51,52}$. As shown in Fig. 3f, $\mathrm{Pt}_{\mathrm{SA}}-\mathrm{NiO} / \mathrm{Ni}$ displays a different intensity maximum with $\mathrm{Pt}_{\mathrm{SA}}-\mathrm{NiO}$ and $\mathrm{Pt}_{\mathrm{SA}}-\mathrm{Ni}$, and especially, the intensity maximum at $7.6 \AA^{-1}$ for $\mathrm{Pt}_{\mathrm{SA}}-\mathrm{NiO} / \mathrm{Ni}$ is lower than that of $\mathrm{Pt}_{\mathrm{SA}}-\mathrm{NiO}\left(8.5 \AA^{-1}\right)$, but high than that of $\mathrm{Pt}_{\mathrm{SA}^{-}} \mathrm{Ni}\left(7.4 \AA^{-1}\right)$, further confirming the interfacial coordination conditions for Pt atoms immobilized in $\mathrm{NiO} / \mathrm{Ni}$. Besides, the intensity maximum at $11.5 \AA^{-1}$ correspondings to Pt-Pt coordination is absent in the fabricated catalysts; further confirming the successful loading of single $\mathrm{Pt}$ atoms in $\mathrm{Ni}$, $\mathrm{NiO} / \mathrm{Ni}$, and $\mathrm{NiO}$ supports.

Theoretical investigations. Based on the above structure analysis, theoretical investigations were performed to disclose the influences of the evolved coordinate configurations of the Pt atom on the electronic structure and catalytic activity of the catalysts. According to the HAADF-STEM and EXAFS measurements, the models for $\mathrm{Pt}_{\mathrm{SA}}-\mathrm{NiO} / \mathrm{Ni}$ were shown in Fig. 4a. Based on the calculated charge density distributions, an increased charge density area along the interface of $\mathrm{NiO} / \mathrm{Ni}$ heterostructure was induced (Fig. S24a, b). After coupling Pt single atom with $\mathrm{NiO} / \mathrm{Ni}$ heterostructure, an electronic structure redistribution at the interfaces of the heterostructure is caused due to the different electronegativity of atoms ( 3.44 for $\mathrm{O}$ atom, 1.91 for $\mathrm{Ni}$, and 2.28 for $\mathrm{Pt}$ ). Especially, charge delocalizing from $\mathrm{Pt}$ to the bonded $\mathrm{O}$ atom and charge localizing from adjacent $\mathrm{Ni}$ atoms to $\mathrm{Pt}$ are displayed. Consequently, a locally enhanced electric field with a half-moon shape area around the

Pt site was generated (Fig. S24c, d), which is more intensive than that of $\mathrm{Pt}_{\mathrm{SA}}-\mathrm{NiO}$ (Fig. 4b) and $\mathrm{Pt}_{\mathrm{SA}}-\mathrm{Ni}$ (Fig. 4c), suggesting Pt single atom coupled with $\mathrm{NiO} / \mathrm{Ni}$ heterostructure could possess the more free electrons to promote the adsorbed $\mathrm{H}$ conversion and $\mathrm{H}_{2}$ evolution ${ }^{24,46}$. Moreover, the projected density of states (PDOS, Figs. 4d and S25) of the single-atom Pt-immobilized $\mathrm{NiO} / \mathrm{Ni}$ heterostructure shows higher occupation than that of the pure $\mathrm{NiO} /$ Ni near the Fermi level, suggesting a promoted electron transfer and higher conductivity of $\mathrm{Pt}_{\mathrm{SA}}-\mathrm{NiO} / \mathrm{Ni}$. The contrast between the $\mathrm{PDOS}$ of $\mathrm{NiO} / \mathrm{Ni}$ and $\mathrm{Pt}_{\mathrm{SA}_{\mathrm{A}}}-\mathrm{NiO} / \mathrm{Ni}$ reveals that the increased DOS of the $\mathrm{Pt}_{\mathrm{SA}}-\mathrm{NiO} / \mathrm{Ni}$ near the Fermi level mainly derives from the contribution of Pt $d$ orbitals (Fig. 4d). These results suggest that the $\mathrm{NiO} / \mathrm{Ni}$ heterostructure-coupled single-atom $\mathrm{Pt}$ can effectively enhance the total $d$-electron domination of the catalyst near the Fermi level, which will benefit the activation of $\mathrm{H}_{2} \mathrm{O}$ and lead to energetically catalytic activity ${ }^{23,53}$. Moreover, the $d$-band features of the $\mathrm{Pt}$ atom in $\mathrm{NiO} / \mathrm{Ni}, \mathrm{NiO}$, and $\mathrm{Ni}$ coordinated configurations are investigated. The wider $5 d$ band and higher density near the Fermi level for $\mathrm{NiO} / \mathrm{Ni}$-supported $\mathrm{Pt}$ atom than that of $\mathrm{Pt}_{\mathrm{SA}}-\mathrm{NiO}$, and $\mathrm{Pt}_{\mathrm{SA}}-\mathrm{Ni}$ (Figs. 4e and S26) suggest that the $\mathrm{NiO} / \mathrm{Ni}$-coupled $\mathrm{Pt}$ atom can induce more free electrons near Pt sites than $\mathrm{Pt}_{\mathrm{SA}}-\mathrm{NiO}$ and $\mathrm{Pt}_{\mathrm{SA}}-\mathrm{Ni}$, which is more favorable for the $\mathrm{H}$ reactants adsorption and 
(a)

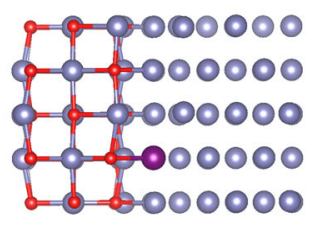

(b)

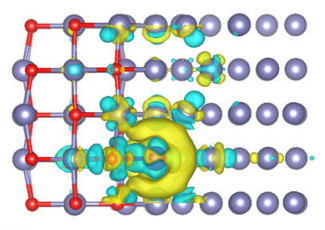

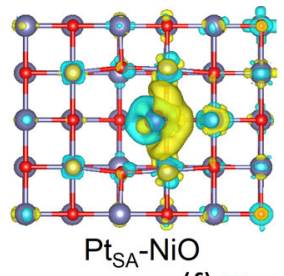

(c)

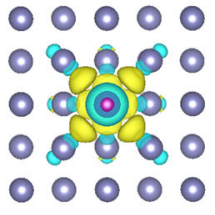

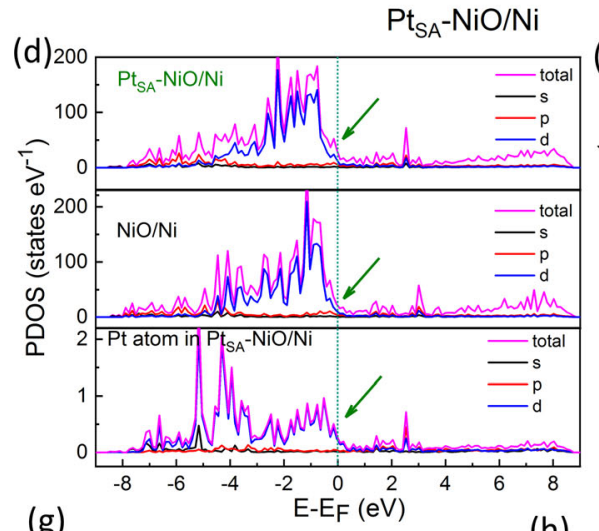

(g)

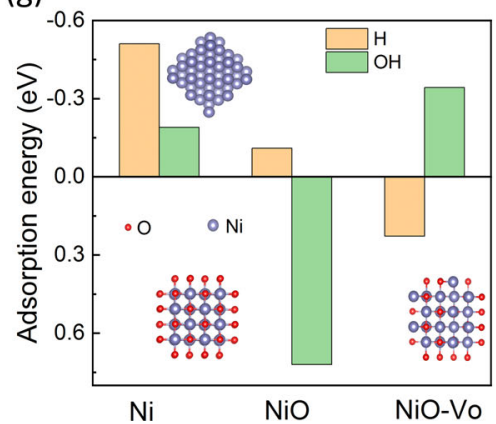

(h)

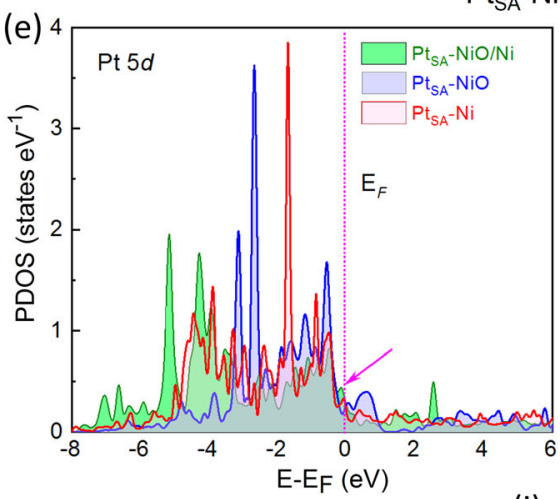

(i)
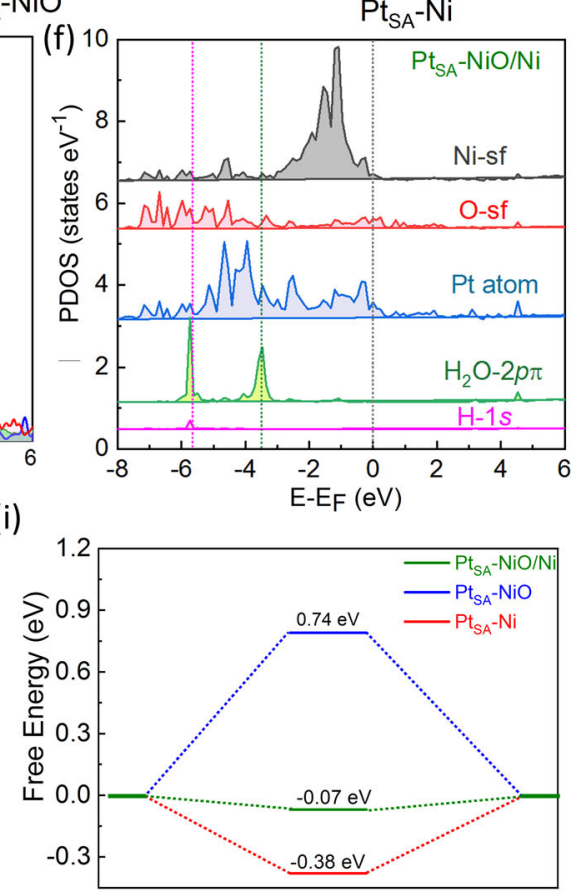

Reaction coordinate

Fig. 4 Theoretical investigations. Computational models and localized electric field distribution of a $\mathrm{Pt}_{\mathrm{SA}}-\mathrm{NiO} / \mathrm{Ni}, \mathbf{b} \mathrm{Pt}_{\mathrm{SA}}-\mathrm{NiO}$, and $\mathbf{c} \mathrm{Pt}_{\mathrm{SA}}-\mathrm{Ni}$. $\mathbf{d} \mathrm{Calculated}$

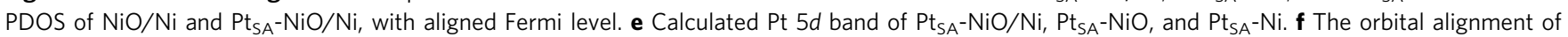
the surficial sites for $\mathrm{Pt}_{\mathrm{SA}}-\mathrm{NiO} / \mathrm{Ni}$ binding with $\mathrm{H}_{2} \mathrm{O}$ molecule. $\mathbf{g}$ Calculated $\mathrm{OH}$-binding energies $\left(\Delta E_{\mathrm{OH}}\right)$ and $\mathrm{H}$ binding energies $\left(\Delta E_{\mathrm{H}}\right)$ for $\mathrm{Ni}$, pure $\mathrm{NiO}$, and $\mathrm{O}$ vacancies-modified $\mathrm{NiO}$ surface. $\mathbf{h}$ Calculated energy barriers of water dissociation kinetic and $\mathbf{i}$ adsorption free energies of $\mathrm{H}^{\star}$ on the surface of the $\mathrm{Pt}_{\mathrm{SA}}-\mathrm{NiO} / \mathrm{Ni}, \mathrm{Pt}_{S A}-\mathrm{NiO}$, and $\mathrm{Pt}_{\mathrm{SA}_{\mathrm{A}}}-\mathrm{Ni}$ catalysts, respectively.

transfer. Besides, the Pt- $5 d$ band of $\mathrm{Pt}_{\mathrm{SA}}-\mathrm{NiO} / \mathrm{Ni}$ also shows a substantially broad range for overlapping with $\mathrm{H}-1 s$ and $\mathrm{H}_{2} \mathrm{O}-2 p \pi$ orbitals (Fig. 4f). Therefore, the Pt site could play a protecting role for stabilizing the Ni valence state and a distributary role by binding $\mathrm{OH}$ and $\mathrm{H}$ species to low the deactivation of absorption sites in case of over-binding of intermediates on the active sites for $\mathrm{NiO} / \mathrm{Ni}$ heterostructure-coupled single-atom $\mathrm{Pt}^{54}$.

Based on the above finding, we further explore the reaction barrier of the fabricated catalysts for $\mathrm{H}_{2} \mathrm{O}$ splitting in alkaline conditions, consisting of the dissociation of $\mathrm{H}_{2} \mathrm{O}$ molecule of Volmer step and the subsequent conversion of $\mathrm{H}$ to $\mathrm{H}_{2}$, which mainly depends on how $\mathrm{OH}$ and $\mathrm{H}$ bond to the active sites on the surface of the catalysts ${ }^{55}$. We found that both $\mathrm{H}$ and $\mathrm{OH}$ bind weakly to the pure $\mathrm{NiO}$ surface, and metallic $\mathrm{Ni}$ surface shows a preference for stabilizing $\mathrm{H}$ (Figs. $4 \mathrm{~g}$ and S27). While $\mathrm{O}$ vacancies-modified $\mathrm{NiO}$ facilitates the adsorption of $\mathrm{OH}$ species (Figs. $4 \mathrm{~g}$ and $\mathrm{S} 28$ ). For $\mathrm{NiO} / \mathrm{Ni}$ composition, the $\mathrm{O}$ vacancies on the interfaces of the $\mathrm{NiO} / \mathrm{Ni}$ heterostructure (Fig. S29) are induced by the crystal-lattice dislocation and phase transition ${ }^{37-39}$. As an integration, $\mathrm{NiO} / \mathrm{Ni}$-coupled single-atom Pt catalyst demonstrates the strongest $\mathrm{H}_{2} \mathrm{O}$ adsorption ability (Fig. S30) and largest energy release of $-0.09 \mathrm{eV}$ for water dissociation in Volmer step (Fig. 4h). Moreover, $\mathrm{Pt}_{\mathrm{SA}}-\mathrm{NiO} / \mathrm{Ni}$ hybrid catalyst only needs the minimum energy barriers $(0.31 \mathrm{eV})$ for the dissociation of $\mathrm{H}_{2} \mathrm{O}$ into $\mathrm{OH}$ and $\mathrm{H}$ under the assistance of $\mathrm{NiO} / \mathrm{Ni}$ interfaces (Fig. S31) calculated by using the Ab Initio Cluster-Continuum Model, confirming the critical role of surface-exposed $\mathrm{NiO} / \mathrm{Ni}$ interfaces for the $\mathrm{H}_{2} \mathrm{O}$ dissociation of Volmer step in alkaline media. In the subsequent step, the $\mathrm{NiO} / \mathrm{Ni}$-supported single-atom $\mathrm{Pt}$ sites at the $\mathrm{NiO} / \mathrm{Ni}$ interfaces act as the proton-acceptor for the recombination of the dissociated proton $\left(\mathrm{H}^{*}\right)$ and $\mathrm{H}_{2}$ evolution due to its near-zero $\mathrm{H}$ binding energy $(-0.07 \mathrm{eV}$, Figs. $4 \mathrm{i}$ and S32) and strong electron supply capacity deriving from locally enhanced charge distribution (Fig. 4a) and the higher occupation of Pt $5 d$ band near Fermi lever (Fig. 4e). Consequently, the overall steps of $\mathrm{Pt}_{\mathrm{SA}}-\mathrm{NiO} / \mathrm{Ni}$ hybrid catalyst for HER in alkaline media are significantly accelerated. Further, the effects of implicit solvation were considered by using VASPsol software as shown in Fig. S33, and $\mathrm{NiO} / \mathrm{Ni}$-coupled single-atom Pt catalyst also demonstrates the minimum energy barriers for the dissociation of $\mathrm{H}_{2} \mathrm{O}$ into $\mathrm{OH}$ and $\mathrm{H}$ than that of $\mathrm{NiO}$-coupled single-atom $\mathrm{Pt}$ and Ni-coupled single-atom $\mathrm{Pt}$ catalyst (Fig. S33a), confirming the critical role of surfaceexposed $\mathrm{NiO} / \mathrm{Ni}$ interfaces for the $\mathrm{H}_{2} \mathrm{O}$ dissociation of Volmer step. Moreover, compared with $\mathrm{Pt}_{\mathrm{SA}}-\mathrm{NiO}$ and $\mathrm{Pt}_{\mathrm{SA}}-\mathrm{Ni}$ systems, the $\mathrm{NiO} / \mathrm{Ni}$-supported single-atom $\mathrm{Pt}$ sites at the $\mathrm{NiO} / \mathrm{Ni}$ interfaces also show near-zero $\mathrm{H}$ binding energy (Fig. S33b), which is consistent with the results of Fig. 4h, i.

Electrocatalytic alkaline HER performances. Based on the structural characterizations and theoretical investigations, the $\mathrm{Pt}$ SAC-coupled with $\mathrm{NiO} / \mathrm{Ni}$ heterostructure possesses the best 

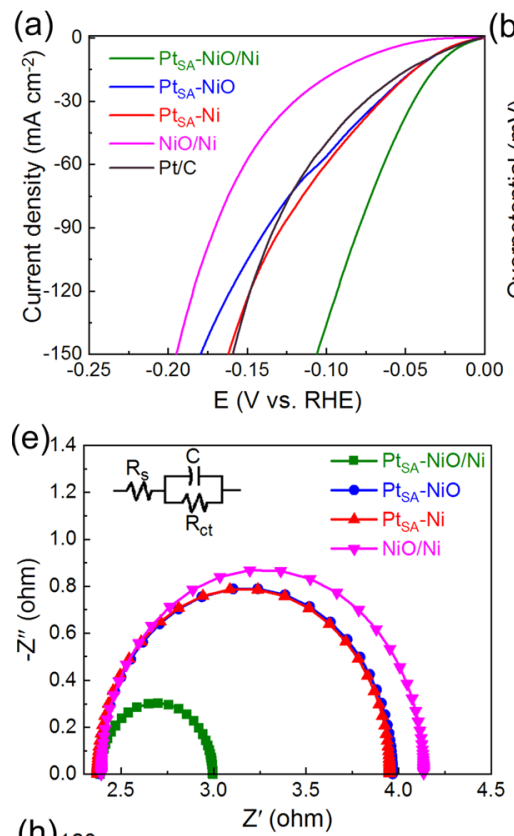
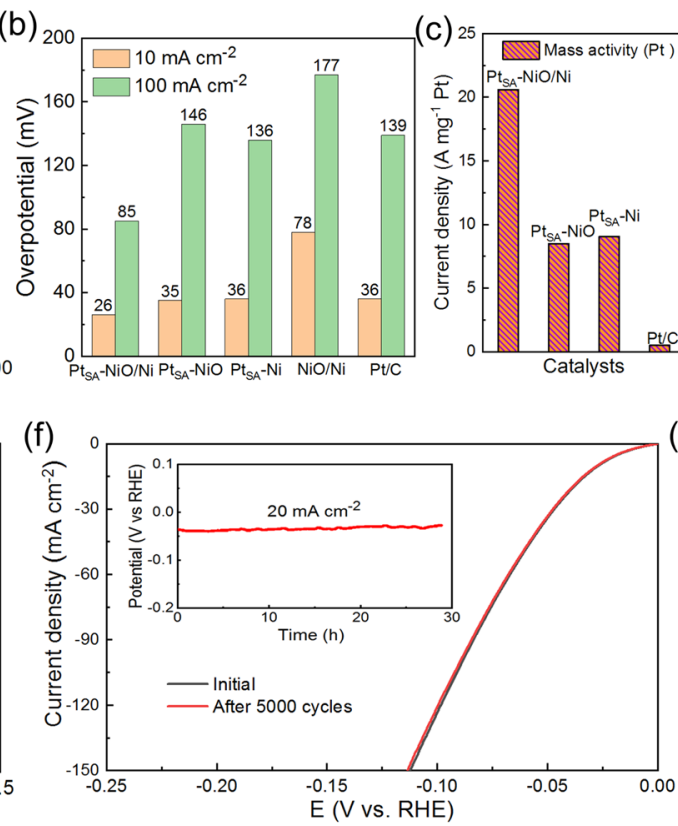

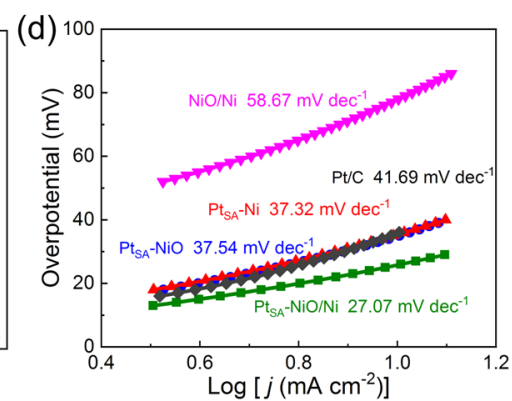

(g)

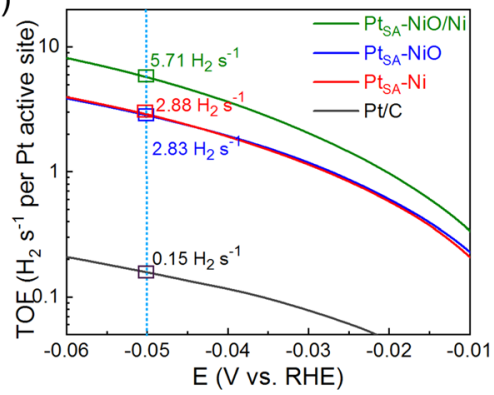

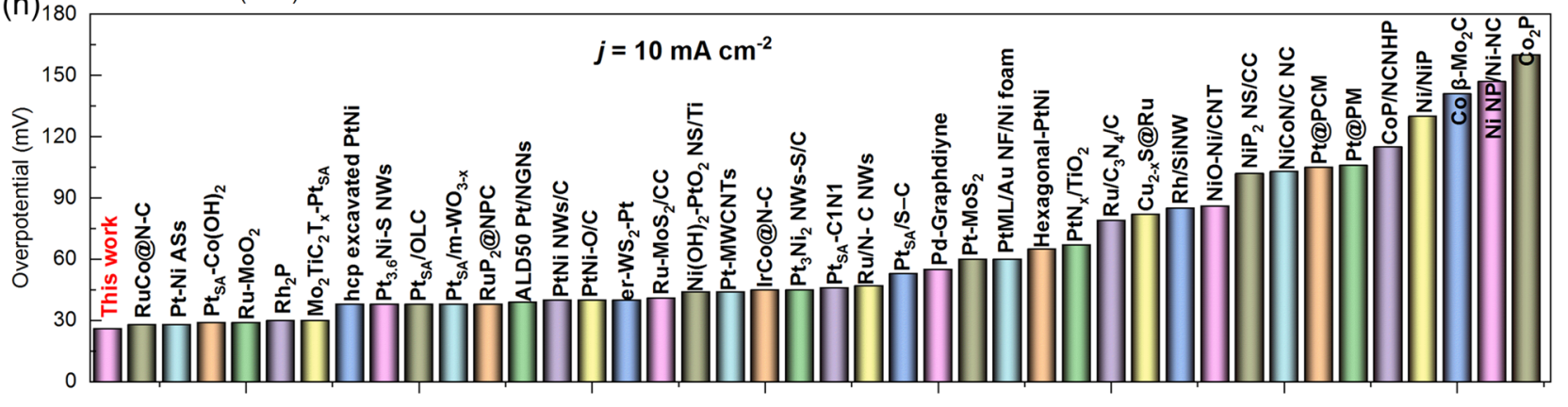

Catalysts for hydrogen evolution reaction

Fig. 5 Electrocatalytic alkaline HER performances of the catalysts in 1-M KOH electrolyte. a HER polarization curves of $\mathrm{Pt}_{\mathrm{SA}}-\mathrm{NiO} / \mathrm{Ni}_{1}, \mathrm{Pt}_{\mathrm{SA}}-\mathrm{NiO}, \mathrm{Pt} t_{S A}-\mathrm{Ni}_{\text {, }}$ $\mathrm{NiO} / \mathrm{Ni}$, and Pt/C. $\mathbf{b}$ The comparison of overpotentials required to achieve 10 and $100 \mathrm{~mA} \mathrm{~cm}^{-2}$ for various catalysts. $\mathbf{c}$ The mass activity of the Pt-based catalysts. d Corresponding Tafel slope originated from LSV curves. e EIS (Electrochemical Impedance Spectroscopy) Nyquist plots of the catalysts. $\mathbf{f}$ Stability test of $\mathrm{Pt}_{\mathrm{SA}}-\mathrm{NiO} / \mathrm{Ni}$ through cyclic potential scanning and chronoamperometry method (inset in $\mathbf{f}$ ). $\mathbf{g}$ TOFs plots of the Pt-based electrocatalysts. $\mathbf{h}$ Comparison of the HER activity for $\mathrm{Pt}_{\mathrm{SA}}-\mathrm{NiO} / \mathrm{Ni}$ with reported catalysts, originating from Table S3.

intrinsic HER activity in alkaline media among the fabricated catalysts. Thus, the electrocatalytic activities of $\mathrm{Pt}_{\mathrm{SA}}-\mathrm{NiO} / \mathrm{Ni}$ for alkaline HER were measured in 1-M KOH solution. As a comparison, the HER performance of $\mathrm{Pt}_{\mathrm{SA}}-\mathrm{NiO}, \mathrm{Pt}_{\mathrm{SA}}-\mathrm{Ni}, \mathrm{NiO} / \mathrm{Ni}$, and $20 \% \mathrm{Pt} / \mathrm{C}$ was also tested under the same conditions. As shown in Fig. 5, the $\mathrm{Pt}_{\mathrm{SA}_{\mathrm{A}}}-\mathrm{NiO} / \mathrm{Ni}$ shows the highest HER performance among all catalysts, and only needs a quite low overpotential of 26 and $85 \mathrm{mV}$ to achieve the current density of 10 and $100 \mathrm{~mA} \mathrm{~cm}{ }^{-2}$, respectively, significantly superior to the $\mathrm{Pt}_{\mathrm{SA}^{-}}$ $\mathrm{NiO}, \mathrm{Pt}_{\mathrm{SA}}-\mathrm{Ni}, \mathrm{NiO} / \mathrm{Ni}$, and the $\mathrm{Pt} / \mathrm{C}$ catalyst (Fig. $5 \mathrm{~b}$ ). Moreover, the mass activity of $\mathrm{Pt}_{\mathrm{SA}}-\mathrm{NiO} / \mathrm{Ni}$ normalized to the loaded $\mathrm{Pt}$ mass (1.14 wt $\%$, inductively coupled plasma-mass spectrometry) at an overpotential of $100 \mathrm{mV}$ is $20.6 \mathrm{~A} \mathrm{mg}^{-1}$, which is $2.4,2.3$, and 41.2 times greater than that of $\mathrm{Pt}_{\mathrm{SA}}-\mathrm{NiO}\left(8.5 \mathrm{~A} \mathrm{mg}^{-1}\right), \mathrm{Pt}_{\mathrm{SA}^{-}}$ $\mathrm{Ni}\left(9.0 \mathrm{~A} \mathrm{mg}^{-1}\right)$, and the commercial Pt/C catalyst $\left(0.5 \mathrm{~A} \mathrm{mg}^{-1}\right)$, respectively. These results suggest that single $\mathrm{Pt}$ atoms coupled with $\mathrm{NiO} / \mathrm{Ni}$ can maximize the alkaline HER activity of Pt-based catalysts, leading to a significant reduction in cost. In addition, the $\mathrm{Pt}_{\mathrm{SA}}-\mathrm{NiO} / \mathrm{Ni}$ exhibits a smaller Tafel slope of $27.07 \mathrm{mV} \mathrm{dec}^{-1}$

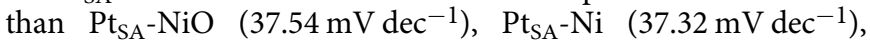
$\mathrm{NiO} / \mathrm{Ni}\left(58.67 \mathrm{mV} \mathrm{dec}^{-1}\right)$, and $\mathrm{Pt} / \mathrm{C}$ catalyst $\left(41.69 \mathrm{mV} \mathrm{dec}^{-1}\right)$, which suggests a typical Volmer-Tafel mechanism for alkaline HER and implies that the rate-determining step of $\mathrm{Pt}_{\mathrm{SA}}-\mathrm{NiO} / \mathrm{Ni}$ is the $\mathrm{H}_{2}$ desorption (Tafel step) rather than the $\mathrm{H}_{2} \mathrm{O}$ dissociation
(Volmer step) ${ }^{34,56}$. Besides, $\mathrm{Pt}_{\mathrm{SA}}-\mathrm{NiO} / \mathrm{Ni}$ catalyst exhibits a 2.0 , and 2.4-fold enhancement in the double-layer capacitance $\left(C_{\mathrm{dl}}\right)$ over $\mathrm{Pt}_{\mathrm{SA}_{\mathrm{A}}}-\mathrm{NiO}$ and $\mathrm{Pt}_{\mathrm{SA}_{\mathrm{A}}}-\mathrm{Ni}$ (Fig. S34), respectively, suggesting the favorable nanostructure with more sites for Pt atoms immobilization and HER. Furthermore, the charge transfer resistance $\left(R_{\mathrm{ct}}\right)$ of $\mathrm{Pt}_{\mathrm{SA}}-\mathrm{NiO} / \mathrm{Ni}\left(0.61 \mathrm{ohm}\right.$, Fig. 5e) is low than that of $\mathrm{Pt}_{\mathrm{SA}}-\mathrm{NiO}$, $\mathrm{Pt}_{\mathrm{SA}_{\mathrm{A}}}-\mathrm{Ni}$, and $\mathrm{NiO} / \mathrm{Ni}$ catalysts, which mainly originates from the introduction of cloth fabric substrate and Ag NWs (Figs. S35 and 36) and the enhanced electronic structure of single Pt atoms coupled with $\mathrm{NiO} / \mathrm{Ni}$.

For real applications, HER catalyzing stability is another essential factor. As present in Fig. 5f, the $\mathrm{Pt}_{\mathrm{SA}}-\mathrm{NiO} / \mathrm{Ni}$ shows high durability in the alkaline electrolyte with negligible loss in HER performance for 5000 cycles or $30 \mathrm{~h}$. The characterizations of $\mathrm{Pt}_{\mathrm{SA}_{\mathrm{A}}}-\mathrm{NiO} / \mathrm{Ni}$ after the stability test, including HAADF-STEM images, elemental mapping, and double-layer capacitance (Figs. S37-39), suggest the negligible structure changes and single-atom dispersion for $\mathrm{Pt}_{\mathrm{SA}}-\mathrm{NiO} / \mathrm{Ni}$ after long-term alkaline HER. Moreover, the turnover frequencies (TOFs) per Pt atom site are analyzed, and the TOFs of $\mathrm{Pt}_{\mathrm{SA}}-\mathrm{NiO} / \mathrm{Ni}\left(5.71 \mathrm{H}_{2} \mathrm{~s}^{-1}\right)$ are 2.02, 1.99, and 38.06 times higher than that of $\mathrm{Pt}_{\mathrm{SA}}-\mathrm{NiO}, \mathrm{Pt}_{\mathrm{SA}}-\mathrm{Ni}$, and $\mathrm{Pt} / \mathrm{C}$ catalyst, respectively (Fig. $5 \mathrm{~g}$ ). To our knowledge, the electrocatalytic HER performances of our $\mathrm{Pt}_{\mathrm{SA}}-\mathrm{NiO} / \mathrm{Ni}$ catalyst in the alkaline media are almost optimal among the reported SACs, 
and are comparable with the performances of catalysts in acid media (Fig. 5h and Table S3), confirming the advance by the constructing single $\mathrm{Pt}$ sites in $\mathrm{NiO} / \mathrm{Ni}$ hybrid system.

Further, based on the highly intrinsic HER activity, the electrocatalytic HER performances of the catalysts in neutral electrolytes containing $1.0-\mathrm{M}$ phosphate buffer solutions $(\mathrm{pH}=$ 7.0) are investigated as shown in Fig. $\mathrm{S} 40 . \mathrm{Pt}_{\mathrm{SA}}-\mathrm{NiO} / \mathrm{Ni}$ shows the highest HER performance among all catalysts in neutral electrolytes, and only needs a quite low overpotential of 27 and $159 \mathrm{mV}$ to achieve the current density of 10 and $100 \mathrm{~mA} \mathrm{~cm}^{-2}$, respectively, significantly superior to the $\mathrm{Pt}_{\mathrm{SA}}-\mathrm{NiO}, \mathrm{Pt}_{\mathrm{SA}}-\mathrm{Ni}, \mathrm{NiO} /$ $\mathrm{Ni}$, and the Pt/C catalyst (Fig. S40b). Moreover, Fig. S40c presents a small Tafel slope $\left(31.94 \mathrm{mV} \mathrm{dec}^{-1}\right)$ for $\mathrm{Pt}_{\mathrm{SA}}-\mathrm{NiO} / \mathrm{Ni}$, lower than that of $\mathrm{Pt}_{\mathrm{SA}}-\mathrm{NiO}\left(47.26 \mathrm{mV} \mathrm{dec}{ }^{-1}\right), \mathrm{Pt}_{\mathrm{SA}}-\mathrm{Ni}\left(40.68 \mathrm{mV} \mathrm{dec}^{-1}\right)$, and $\mathrm{Pt} / \mathrm{C}$ catalyst $\left(42.40 \mathrm{mV} \mathrm{dec}^{-1}\right)$, revealing fast HER kinetics for $\mathrm{NiO} / \mathrm{Ni}$ heterostructure-coupled $\mathrm{Pt}$ single atoms. The above merits of the $\mathrm{Pt}_{\mathrm{SA}}-\mathrm{NiO} / \mathrm{Ni}$, including low overpotential and Tafel slope, are superior to most previously reported catalysts in the neutral solution (Fig. S40d and Table S4), further confirming the advance by the constructing single $\mathrm{Pt}$ sites in $\mathrm{NiO} / \mathrm{Ni}$ hybrid system.

\section{Discussion}

In summary, we reported a single-atom $\mathrm{Pt}\left(\mathrm{Pt}_{\mathrm{SA}}\right)$ immobilized $\mathrm{NiO} / \mathrm{Ni}$ heterostructure nanosheets on $\mathrm{Ag}$ NWs network nanocomposite by the facile electrodeposition strategy, which serves as an efficient electrocatalyst for vigorous hydrogen production in alkaline media. Theoretical calculations revealed that the Pt SACs coupled with $\mathrm{NiO} / \mathrm{Ni}$ heterostructure could efficiently tailoring water dissociation energy for accelerating alkaline HER. In particular, the dual active sites consisting of metallic $\mathrm{Ni}$ sites and $\mathrm{O}$ vacancies-modified $\mathrm{NiO}$ sites near the interfaces of $\mathrm{NiO} / \mathrm{Ni}$ have the preferred adsorption affinity toward both $\mathrm{OH}^{*}$ and $\mathrm{H}^{*}$, which facilitates water adsorption and reaches a barrier-free water dissociation step with the lowest energy barrier of $0.31 \mathrm{eV}$ in Volmer step (step (i)) for $\mathrm{Pt}_{\mathrm{SA}}-\mathrm{NiO} / \mathrm{Ni}$ compared with that of $\mathrm{Pt}_{\mathrm{SA}}-\mathrm{Ni}$ $(0.47 \mathrm{eV})$ and $\mathrm{Pt}_{\mathrm{SA}}-\mathrm{NiO}(1.42 \mathrm{eV})$ catalysts. Besides, fixing $\mathrm{Pt}$ atoms at the $\mathrm{NiO} / \mathrm{Ni}$ interfaces induce a higher occupation of the Pt $5 d$ band at the Fermi level and the more suitable $\mathrm{H}$ binding energy $\left(\Delta G_{\mathrm{H}^{*}},-0.07 \mathrm{eV}\right)$ than that of Pt atoms at the $\mathrm{NiO}\left(\Delta G_{\mathrm{H}^{*}}\right.$, $0.74 \mathrm{eV})$ and $\mathrm{Ni}\left(\Delta G_{\mathrm{H}^{*}},-0.38 \mathrm{eV}\right)$, which efficiently promotes the $\mathrm{H}^{*}$ conversion and $\mathrm{H}_{2}$ desorption, thus accelerating overall alkaline HER. The further enhancement of alkaline HER performance was achieved by introducing the Ag NWs network into $2 \mathrm{D} \mathrm{Pt}_{\mathrm{SA}}-\mathrm{NiO} / \mathrm{Ni}$ nanosheets to construct a seamlessly conductive $3 \mathrm{D}$ nanostructure. The unique nanostructural feature and highly conductive Ag NWs network provide abundant active sites and accessible channels for electron transfer and mass transport. Consequently, the $3 \mathrm{D} \mathrm{Pt}_{\mathrm{SA}}-\mathrm{NiO} / \mathrm{Ni}$ catalyst shows outstanding HER performances in alkaline conditions with a quite low overpotential of $26 \mathrm{mV}$ at a current density of $10 \mathrm{~mA} \mathrm{~cm}^{-2}$ and high mass activity of $20.6 \mathrm{~A} \mathrm{mg}^{-1} \mathrm{Pt}$ in $1-\mathrm{M} \mathrm{KOH}$, significantly outperforming the reported catalysts. This study opens an efficient avenue for the advance of SACs by introducing a water dissociation kinetic-oriented material system.

\section{Methods \\ Synthesis of Ag NWs. An oil bath method was used to synthesize Ag NWs according to our previous report ${ }^{57}$. Specifically, a mix solution consisting of ethylene glycol, $\mathrm{FeCl}_{3}(7.19 \mathrm{mM}), \mathrm{AgNO}_{3}(0.051 \mathrm{M})$, and polyvinylpyrrolidone $(0.012 \mathrm{M})$ was heat and maintained under an oil bath pan with $110^{\circ} \mathrm{C}$ for $12 \mathrm{~h}$. After that, the generated precipitate was washed with acetone and alcohol to get the pure Ag NWs. Subsequently, the Ag NWs were uniformly dispersed on a flexible cloth fabric by spray coating technology to fabricate a conductive network.}

Synthesis of $\mathbf{N i O} / \mathbf{N i}$ on $\mathbf{A g} \mathbf{N W s}$. Ni/NiO is grown on $\mathrm{Ag}$ NWs network by a facile electrodeposition process in the aqueous electrolyte of $20-\mathrm{mM}$
$\mathrm{C}_{4} \mathrm{H}_{6} \mathrm{NiO}_{4} \cdot 4 \mathrm{H}_{2} \mathrm{O}$ according to the recent report ${ }^{36}$. The electrodeposition process was performed by chronoamperometry method with $-3 \mathrm{~V}$ versus SCE for $200 \mathrm{~s}$ under a standard three-electrode system, in which graphite sheet acted as a counter electrode, SCE acted as a reference electrode, and the fabricated Ag NWs network loaded on the cloth was directly used as working electrode. The obtained samples were washed with deionized water and then dried at room temperature.

Synthesis of NiO on $\mathbf{A g ~ N W s . ~ N i O ~ i s ~ g r o w n ~ o n ~ A g ~ N W s ~ n e t w o r k ~ b y ~ t h e ~ e l e c - ~}$ trodeposition process with $-1 \mathrm{~V}$ versus SCE for $600 \mathrm{~s}$ in an aqueous electrolyte of $20-\mathrm{mM} \mathrm{C}_{4} \mathrm{H}_{6} \mathrm{NiO}_{4} \cdot 4 \mathrm{H}_{2} \mathrm{O}$. The obtained samples were washed with deionized water and then dried at room temperature.

Synthesis of Ni on Ag NWs. Metallic Ni is grown on $\mathrm{Ag}$ NWs network by the electrodeposition process in an aqueous solution consisting of $0.10-\mathrm{M} \mathrm{NiCl}_{2}, 0.09$ $\mathrm{M} \mathrm{H}_{3} \mathrm{BO}_{3}$, and a solvent containing ethanol and deionized water with 2:5 in volume ratio. The electrodeposition process was performed by chronoamperometry with $-1.2 \mathrm{~V}$ versus SCE for $200 \mathrm{~s}$. The obtained samples were washed with deionized water and then dried at room temperature.

Synthesis of $\mathbf{P t}_{\mathbf{S A}}-\mathbf{N i O} / \mathbf{N i}$ on $\mathbf{A g} \mathbf{N W s}$. $\mathrm{Pt}_{\mathrm{SA}_{A}}-\mathrm{NiO} / \mathrm{Ni}$ on $\mathrm{Ag} \mathrm{NWs}$ was fabricated by the electrochemical reduction process in the three-electrode system, in which the fabricated $\mathrm{NiO} / \mathrm{Ni}$ on $\mathrm{Ag} \mathrm{NWs}$ was performed as the working electrode, graphite sheet acted as a counter electrode, saturated calomel electrode acted as a reference electrode. The corresponding electrochemical process was carried out by multi-cycle cathode polarization in $1-\mathrm{M} \mathrm{KOH}$ solution containing $50-\mu \mathrm{M} \mathrm{H}_{2} \mathrm{PtCl}_{6}$ with a scan rate of $50 \mathrm{mV} \mathrm{s}^{-1}$ between 0 and $-0.50 \mathrm{~V}$ versus RHE for 200 cycles.

Synthesis of $\mathbf{P t}_{\mathbf{S A}}-\mathbf{N i O}$ on $\mathbf{A g} \mathbf{N W s}$. $\mathrm{Pt}_{\mathrm{SA}}-\mathrm{NiO}$ on $\mathrm{Ag}$ NWs was fabricated by multi-cycle cathode polarization in $1-\mathrm{M} \mathrm{KOH}$ solution containing $50-\mu \mathrm{M} \mathrm{H}_{2} \mathrm{PtCl}_{6}$ with a scan rate of $50 \mathrm{mV} \mathrm{s}^{-1}$ between 0 and $-0.50 \mathrm{~V}$ versus RHE for 200 cycles.

Synthesis of $\mathbf{P t}_{\mathbf{S A}}-\mathbf{N i}$ on $\mathbf{A g} \mathbf{N W s}$. $\mathrm{Pt}_{\mathrm{SA}}-\mathrm{Ni}$ on $\mathrm{Ag}$ NWs was fabricated by multicycle cathode polarization in $1-\mathrm{M} \mathrm{KOH}$ solution containing $50-\mu \mathrm{M} \mathrm{H}_{2} \mathrm{PtCl}_{6}$ with a scan rate of $50 \mathrm{mV} \mathrm{s}^{-1}$ between 0 and $-0.50 \mathrm{~V}$ versus RHE for 200 cycles.

Characterizations. The morphology measurement of the synthesized catalysts was performed by SEM (GeminiSEM 300). HRTEM images, HAADF-STEM images, and STEM-EDS mapping images were obtained by an FEI Titan $\mathrm{G}^{2}$ microscope equipped with an aberration corrector for probe-forming lens and a Bruker SuperX energy dispersive spectrometer operated at $300 \mathrm{kV}$. The Pt contents in the catalysts were measured by inductively coupled plasma optical emission spectrometry. The XPS spectra of elementals were tested by a surface analysis system (ESCALAB250Xi). The phase and crystal information were obtained by $\mathrm{Cu} \mathrm{Ka}$ radiation in an X-ray diffractometer (XRD, Bruker, D8 Advance Davinci). The EXAFS measurement of the $\mathrm{Pt}_{\mathrm{SA}}-\mathrm{NiO} / \mathrm{Ni}, \mathrm{Pt}_{\mathrm{SA}}-\mathrm{NiO}$, and $\mathrm{Pt}_{\mathrm{SA}}-\mathrm{NiO} / \mathrm{Ni}$ at the $\mathrm{Pt} L_{3}$-edge was performed at 1W1B station at the Beijing Synchrotron Radiation Facility. Data analysis and fitting were performed with Athena and Artemis in the Demeter package.

Electrochemical measurements. All electrochemical measurements were finished by an electrochemical workstation (CHI 660E) with a three-electrode configuration, in which fabricated catalysts were directly employed as the working electrode, graphite sheet acted as a counter electrode, saturated calomel electrode acted as a reference electrode. All the presented potential in this work was transferred to RHE according to an experimental method ${ }^{53}$. LSV with $95 \%$ iR-corrections were tested under the potential range from 0.05 to $-0.5 \mathrm{~V}$ and the scan rate of $5 \mathrm{mV} \mathrm{s}^{-1}$. EIS was obtained by a frequency range from $100 \mathrm{k}$ to $0.1 \mathrm{~Hz}$ with an overpotential of $230 \mathrm{mV}$ versus RHE. For the preparation of 3D Pt/C@Ni foam, $5 \mathrm{mg} \mathrm{20-wt \%} \mathrm{Pt/C}$ was dispersed in $0.9-\mathrm{mL}$ alcohol containing $0.1 \mathrm{~mL} 5$-wt\% Nafion solution to form a homogeneous ink. Then, the obtained ink was coated on the Ni foam and dried in air to form a porous Pt/C@Ni foam electrode.

DFT theoretical calculations. All the structural optimizations, charge density difference analysis, Bader charge analysis, and energy calculations were carried out based on DFT as implemented in the Vienna Ab initio Simulation Package ${ }^{58-60}$. The projector-augmented wave method was implemented to calculate the interaction between the ionic cores and valence electrons ${ }^{61,62}$. The

Perdew-Burke-Ernzerhof approach of spin-polarized generalized gradient approximation was used to describe the exchange-correlation energy ${ }^{63}$. Calculations were performed with the cutoff plane-wave kinetic energy of $500 \mathrm{eV}$, and $8 \times$ $4 \times 1 k$-mesh grids were employed for the integration of the Brillouin zone. Electronic relaxation was undertaken to utilize the conjugate-gradient method ${ }^{64}$ with the total energy convergence criterion being $10^{-5} \mathrm{eV}$. Geometry optimization was employed by the quasi-Newton algorithm ${ }^{65,66}$ until all the residual forces on unconstrained atoms $<0.01 \mathrm{eV} / \AA$. Climbing image nudge elastic band calculations $s^{67}$ were employed for finding transition barriers with the initial configuration of $\mathrm{H}_{2} \mathrm{O}$ absorbed on the catalyst surface and final configuration of $\mathrm{OH}+$ 
$\mathrm{H}$ absorbed on the catalyst surface. To ensure the initial configuration correctly, an $\mathrm{H}_{2} \mathrm{O}$ molecule was deposited on the catalyst surface and relaxed for calculating its local minimum total energy on different sites, and the last one is the initially stable configuration. The final configuration is also found by relaxing $\mathrm{OH}$ and $\mathrm{H}$ near the $\mathrm{H}_{2} \mathrm{O}$ absorbed site of the initial configuration. Next, The equation for calculating adsorption enthalpy $\Delta \mathrm{E}_{\mathrm{H}^{*}}$ as the following:

$$
\Delta E_{\mathrm{H}^{*}}=E_{\text {slab }+\mathrm{H}}-E_{\text {slab }}-\frac{1}{2} E_{\mathrm{H}_{2}}
$$

where the $E_{\text {slab }+\mathrm{H}}$ is the total enthalpy of $\mathrm{H}$ adsorbing on the catalysts, the enthalpy of the catalysts is $E_{\text {slab}}$, and the $\mathrm{H}_{2}$ enthalpy is $E_{\mathrm{H}_{2}}$.

The $\mathrm{H}$ and $\mathrm{H}_{2} \mathrm{O}$ absorbing on the slabs were investigated by comparing the formation energy of different sites. The equation for calculating adsorption enthalpy $\Delta \mathrm{E}_{\mathrm{H}^{*}}$ as the following:

$$
\Delta E_{\mathrm{H}^{*}}=E_{\text {slab }+\mathrm{H}}-E_{\text {slab }}-\frac{1}{2} E_{\mathrm{H}_{2}}
$$

where the $E_{\text {slab }+\mathrm{H}}$ is the total enthalpy of $\mathrm{H}$ adsorbing on the catalysts, enthalpy of the catalysts is $E_{\text {slab }}$, the $\mathrm{H}_{2}$ enthalpy is $E_{\mathrm{H}_{2}}$. As similar, the equation for calculating the $\mathrm{H}_{2} \mathrm{O}$ adsorption enthalpy $\Delta E_{\mathrm{H}_{2} \mathrm{O}^{*}}$ as the following:

$$
\Delta E_{\mathrm{H}_{2} \mathrm{O}^{*}}=E_{\text {slab }+\mathrm{H}_{2} \mathrm{O}}-E_{\text {slab }}-E_{\mathrm{H}_{2} \mathrm{O}} \text { * }
$$

The free energy of adsorbed $\mathrm{H}$ and $\mathrm{H}_{2} \mathrm{O}$ as follows:

$$
\begin{gathered}
\Delta G_{\mathrm{H}^{*}}=\Delta E_{\mathrm{H}^{*}}+\Delta E_{\mathrm{ZPE}}-T \Delta S \\
\Delta G_{\mathrm{H}_{2} \mathrm{O}^{*}}=\Delta E_{\mathrm{H}_{2} \mathrm{O}^{*}}+\Delta E_{\mathrm{ZPE}}-T \Delta S
\end{gathered}
$$

where $\Delta E_{\mathrm{H}^{*}}$ represent the $\mathrm{H}$ adsorption energy and $\Delta E_{\mathrm{H}_{2} \mathrm{O}}$ * represent the $\mathrm{H}_{2} \mathrm{O}$ adsorption energy, and $\Delta E_{\mathrm{ZPE}}$ represents the difference related to the zero-point energy between the gas phase and the adsorbed state.

\section{Data availability}

The data that support the findings of this work are available from the corresponding author upon reasonable request.

Received: 25 January 2021; Accepted: 1 June 2021; Published online: 18 June 2021

\section{References}

1. Turner, J. A. Sustainable hydrogen production. Science 305, 972-974 (2004).

2. Dresselhaus, M. et al. Alternative energy technologies. Nature 414, 332-337 (2001).

3. Jiao, Y. et al. Design of electrocatalysts for oxygen-and hydrogen-involving energy conversion reactions. Chem. Soc. Rev. 44, 2060-2086 (2015).

4. Wang, P. et al. Phase and interface engineering of platinum-nickel nanowires for efficient electrochemical hydrogen evolution. Angew. Chem. Int. Ed. 128, 13051-13055 (2016).

5. Morales-Guio, C. G. et al. Nanostructured hydrotreating catalysts for electrochemical hydrogen evolution. Chem. Soc. Rev. 43, 6555-6569 (2014).

6. Lv, H. et al. A new core/shell NiAu/Au nanoparticle catalyst with Pt-like activity for hydrogen evolution reaction. J. Am. Chem. Soc. 137, 5859-5862 (2015).

7. Laursen, A. et al. Nanocrystalline $\mathrm{Ni}_{5} \mathrm{P}_{4}$ : a hydrogen evolution electrocatalyst of exceptional efficiency in both alkaline and acidic media. Energy Environ. Sci. 8, 1027-1034 (2015).

8. Laursen, A. B. et al. Climbing the volcano of electrocatalytic activity while avoiding catalyst corrosion: $\mathrm{Ni}_{3} \mathrm{P}$, a hydrogen evolution electrocatalyst stable in both acid and alkali. ACS Cat. 8, 4408-4419 (2018).

9. Lai, J. et al. Strongly coupled nickel-cobalt nitrides/carbon hybrid nanocages with pt-like activity for hydrogen evolution catalysis. Adv. Mater. 31, 1805541 (2019).

10. Xie, X. et al. Electrocatalytic hydrogen evolution in neutral ph solutions: dualphase synergy. ACS Cat. 9, 8712-8718 (2019).

11. Lv, F. et al. Ir-based alloy nanoflowers with optimized hydrogen binding energy as bifunctional electrocatalysts for overall water splitting. Small Methods 4, 1900129 (2020).

12. Li, Y. et al. Ru nanoassembly catalysts for hydrogen evolution and oxidation reactions in electrolytes at various $\mathrm{pH}$ values. Appl. Catal. B. 258, 117952 (2019).

13. Jones, J. et al. Thermally stable single-atom platinum-on-ceria catalysts via atom trapping. Science 353, 150-154 (2016).

14. $\mathrm{Li}, \mathrm{H}$. et al. Synergetic interaction between neighbouring platinum monomers in $\mathrm{CO}_{2}$ hydrogenation. Nat. Nanotech. 13, 411-417 (2018).

15. Qiao, B. et al. Single-atom catalysis of $\mathrm{CO}$ oxidation using $\mathrm{Pt}_{1} / \mathrm{FeO}_{x}$. Nat. Chem. 3, 634-641 (2011).

16. Li, X. et al. Single-atom Pt as co-catalyst for enhanced photocatalytic $\mathrm{H}_{2}$ evolution. Adv. Mater. 28, 2427-2431 (2016).
17. Ledezma-Yanez, I. et al. Interfacial water reorganization as a pH-dependent descriptor of the hydrogen evolution rate on platinum electrodes. Nat. Energy 2, 1-7 (2017).

18. Subbaraman, R. et al. Enhancing hydrogen evolution activity in water splitting by tailoring $\mathrm{Li}^{+}-\mathrm{Ni}(\mathrm{OH})_{2}-\mathrm{Pt}$ interfaces. Science 334, 1256-1260 (2011).

19. Stamenkovic, V. R. et al. Energy and fuels from electrochemical interfaces. Nat. Mater. 16, 57-69 (2017).

20. Durst, J. et al. New insights into the electrochemical hydrogen oxidation and evolution reaction mechanism. Energy Environ. Sci. 7, 2255-2260 (2014).

21. Wang, D. et al. Atomic and electronic modulation of self-supported nickelvanadium layered double hydroxide to accelerate water splitting kinetics. Nat. Commun. 10, 1-12 (2019).

22. Zhang, J. et al. Efficient hydrogen production on $\mathrm{MoNi}_{4}$ electrocatalysts with fast water dissociation kinetics. Nat. Commun. 8, 1-8 (2017).

23. Zhang, J. et al. Single platinum atoms immobilized on an MXene as an efficient catalyst for the hydrogen evolution reaction. Nat. Catal. 1, 985-992 (2018).

24. Liu, D. et al. Atomically dispersed platinum supported on curved carbon supports for efficient electrocatalytic hydrogen evolution. Nat. Energy 4, 512-518 (2019)

25. Jiang, K. et al. Single platinum atoms embedded in nanoporous cobalt selenide as electrocatalyst for accelerating hydrogen evolution reaction. Nat. Commun. 10, 1743 (2019)

26. Deng, J. et al. Triggering the electrocatalytic hydrogen evolution activity of inert two-dimensional $\mathrm{MoS}_{2}$ surface via single-atom metal doping. Energy Environ. Sci. 8, 1594-1601 (2015).

27. Cheng, N. et al. Platinum single-atom and cluster catalysis of the hydrogen evolution reaction. Nat. Commun. 7, 13638 (2016).

28. Huabin, Z. et al. Dynamic traction of lattice-confined platinum atoms into mesoporous carbon matrix for hydrogen evolution reaction. Sci. Adv. 4, eaao6657 (2018).

29. Zhang, B. et al. Dual-descriptor tailoring: the hydroxyl adsorption energydependent hydrogen evolution kinetics of high-valance state doped $\mathrm{Ni}_{3} \mathrm{~N}$ in alkaline media. ACS Cat. 9, 9332-9338 (2019).

30. Subbaraman, R. et al. Trends in activity for the water electrolyser reactions on 3d M(Ni,Co,Fe,Mn) hydr(oxy)oxide catalysts. Nat. Mater. 11, 550-557 (2012).

31. Sheng, W. et al. Correlating hydrogen oxidation and evolution activity on platinum at different $\mathrm{pH}$ with measured hydrogen binding energy. Nat. Commun. 6, 5848 (2015).

32. Chen, G. et al. Accelerated hydrogen evolution kinetics on NiFe-layered double hydroxide electrocatalysts by tailoring water dissociation active sites. Adv. Mater. 30, 1706279 (2018).

33. Li, F. et al. Balancing hydrogen adsorption/desorption by orbital modulation for efficient hydrogen evolution catalysis. Nat. Commun. 10, 1-7 (2019).

34. Huang, J. et al. Boosting hydrogen transfer during volmer reaction at oxides/ metal nanocomposites for efficient alkaline hydrogen evolution. ACS Energy Lett. 4, 3002-3010 (2019).

35. Zhou, K. et al. A Setaria-inflorescence-structured catalyst based on nickelcobalt wrapped silver nanowire conductive networks for highly efficient hydrogen evolution. J. Mater. Chem. A 7, 26566-26573 (2019).

36. Li, X. et al. Sequential electrodeposition of bifunctional catalytically active structures in $\mathrm{MoO}_{3} / \mathrm{Ni}-\mathrm{NiO}$ composite electrocatalysts for selective hydrogen and oxygen evolution. Adv. Mater. 32, 2003414 (2020).

37. Han, S.-K. et al. Precursor triggering synthesis of self-coupled sulfide polymorphs with enhanced photoelectrochemical properties. J. Am. Chem. Soc. 138, 12913-12919 (2016).

38. $\mathrm{Wu}, \mathrm{X}$.-J. et al. Controlled growth of high-density $\mathrm{CdS}$ and CdSe nanorod arrays on selective facets of two-dimensional semiconductor nanoplates. Nat. Chem. 8, 470-475 (2016).

39. Feng, Y. et al. Selectively anchoring Pt single atoms at hetero-interfaces of $\gamma$ $\mathrm{Al}_{2} \mathrm{O}_{3} / \mathrm{NiS}$ to promote the hydrogen evolution reaction. J. Mater. Chem. A 6 , 11783-11789 (2018).

40. Hsu, P.-C. et al. Hydrogen bubbles and the growth morphology of ramified zinc by electrodeposition. J. Electrochem. Soc. 155, D400 (2008).

41. $\mathrm{Xu}, \mathrm{D}$. et al. Simple coordination complex-derived Ni NP anchored N-doped porous carbons with high performance for reduction of nitroarenes. CrystEngComm 19, 6612-6619 (2017).

42. Xu, X. et al. The preparation of hierarchical tubular structures comprised of $\mathrm{NiO}$ nanosheets with enhanced supercapacitive performance. RSC Adv. 4, 3181-3187 (2014).

43. Ye, S. et al. Highly stable single Pt atomic sites anchored on aniline-stacked graphene for hydrogen evolution reaction. Energy Environ. Sci. 12, 1000-1007 (2019).

44. Hunt, S. T. et al. Activating earth-abundant electrocatalysts for efficient, low-cost hydrogen evolution/oxidation: sub-monolayer platinum coatings on titanium tungsten carbide nanoparticles. Energy Environ. Sci. 9, 3290-3301 (2016).

45. Huang, X. et al. High-performance transition metal-doped $\mathrm{Pt}_{3} \mathrm{Ni}$ octahedra for oxygen reduction reaction. Science 348, 1230-1234 (2015). 
46. Zhou, K. et al. Seamlessly conductive $\mathrm{Co}(\mathrm{OH})_{2}$ tailored atomically dispersed pt electrocatalyst in hierarchical nanostructure for efficient hydrogen evolution reaction. Energy Environ. Sci. 13, 3082-3092 (2020).

47. Romanchenko, A. et al. X-ray photoelectron spectroscopy (XPS) study of the products formed on sulfide minerals upon the interaction with aqueous platinum (IV) chloride complexes. Minerals 8, 578 (2018).

48. Cai, W. et al. Platinum-trimer decorated cobalt-palladium core-shell nanocatalyst with promising performance for oxygen reduction reaction. Nat. Commun. 10, 440 (2019)

49. Fei, H. et al. Atomic cobalt on nitrogen-doped graphene for hydrogen generation. Nat. Commun. 6, 8668 (2015).

50. Kwak, J. et al. Coordinatively unsaturated $\mathrm{Al}^{3+}$ centers as binding sites for active catalyst phases of platinum on $-\mathrm{Al}_{2} \mathrm{O}_{3}$. Science $325,1670-1673$ (2009).

51. Savinelli, R. et al. Wavelet transform EXAFS analysis of mono- and dimolybdate model compounds and a Mo/HZSM-5 dehydroaromatization catalyst. Phys. Chem. Chem. Phys. 12, 5660-5667 (2010).

52. Funke, $\mathrm{H}$. et al. Wavelet analysis of extended $\mathrm{x}$-ray absorption fine structure data. Phys. Rev. B 71(9), 094110-094110.7 (2005).

53. Fang, S. et al. Uncovering near-free platinum single-atom dynamics during electrochemical hydrogen evolution reaction. Nat. Commun. 11, 1029 (2020).

54. Yin, J. et al. Iridium single atoms coupling with oxygen vacancies boosts oxygen evolution reaction in acid media. J. Am. Chem. Soc. 142, 18378-18386 (2020).

55. Dinh, C. T. et al. Multi-site electrocatalysts for hydrogen evolution in neutral media by destabilization of water molecules. Nat. Energy 4, 107-114 (2019).

56. Shi, Y. et al. Recent advances in transition metal phosphide nanomaterials: Synthesis and applications in hydrogen evolution reaction. Chem. Soc. Rev. 45, 1529-1541 (2016).

57. Zhou, K. L. et al. Highly stable transparent conductive electrodes based on silver-platinum alloy-walled hollow nanowires for optoelectronic devices. ACS Appl. Mater. Interfaces 10, 36128-36135 (2018).

58. Kresse, G. G. et al. Efficiency of ab-initio total energy calculations for metals and semiconductors using a plane-wave basis set. Comput. Mater. Sci. 6 , 15-50 (1996).

59. Kresse, G. G. et al. Efficient iterative schemes for ab initio total-energy calculations using a plane-wave basis set. Phys. Rev. B 54, 11169-11186 (1996).

60. Kresse, G. G. et al. Ab initio molecular-dynamics simulation of the liquidmetal-amorphous-semiconductor transition in germanium. Phys. Rev. B 49 14251-14269 (1994).

61. Blöchl, P. et al. Projector augmented-wave method. Phys. Rev. B 50, 17953-17979 (1994).

62. Kresse, G. G. et al. From ultrasoft pseudopotentials to the projector augmented-wave method. Phys. Rev. B 59, 1758-1775 (1999).

63. Perdew, J. P. et al. Generalized gradient approximation made simple. Phys. Rev. Lett. 77, 3865-3868 (1996).

64. Payne, M. C. et al. Iterative minimization techniques for ab initio total-energy calculations: molecular dynamics and conjugate gradients. Rev. Mod. Phys. 64, 1045-1097 (1992).

65. Methfessel, M. et al. High-precision sampling for Brillouin-zone integration in metals. Phys. Rev. B 40, 3616-3621 (1989).

66. Pulay, P. Convergence acceleration of iterative sequences. The case of SCF iteration. Chem. Phys. Lett. 73, 393-398 (1980).
67. Henkelman, G. et al. A climbing image nudged elastic band method for finding saddle points and minimum energy paths. J. Chem. Phys. 113, 9901-9904 (2000)

\section{Acknowledgements}

This work was supported by the National Natural Science Foundation of China (NSFC) (Grant No. 52070006, 11804012, 12074017), the Scientific and Technological Development Project of the Beijing Education Committee (No. KZ201710005009), and the Beijing Municipal Education Commission (Grant No. KM201910005009), the Beijing municipal high level innovative team building program (IDHT20190503) and the National Natural Science Fund for Innovative Research Groups of China (51621003).

\section{Author contributions}

H.W. and H.Y. supervised this study. K.L.Z. conceived the idea. K.L.Z., Z.W., C.W., an Y.J. planned and carried out the experiments, collected, and analyzed the experimental data. X.K. and Q.Z. performed SEM and TEM characterizations. C.W. and K.L.Z. conducted theoretical calculations. K.L.Z., J.L., and C.B.H. wrote the paper. All the authors have discussed the results and wrote the paper together.

\section{Competing interests}

The authors declare no competing interests.

\section{Additional information}

Supplementary information The online version contains supplementary material available at https://doi.org/10.1038/s41467-021-24079-8.

Correspondence and requests for materials should be addressed to C.B.H., X.K. or H.W.

Peer review information Nature Communications thanks the anonymous reviewers for their contributions to the peer review of this work. Peer review reports are available.

Reprints and permission information is available at http://www.nature.com/reprints

Publisher's note Springer Nature remains neutral with regard to jurisdictional claims in published maps and institutional affiliations.

\footnotetext{
(c) (i) Open Access This article is licensed under a Creative Commons Attribution 4.0 International License, which permits use, sharing, adaptation, distribution and reproduction in any medium or format, as long as you give appropriate credit to the original author(s) and the source, provide a link to the Creative Commons license, and indicate if changes were made. The images or other third party material in this article are included in the article's Creative Commons license, unless indicated otherwise in a credit line to the material. If material is not included in the article's Creative Commons license and your intended use is not permitted by statutory regulation or exceeds the permitted use, you will need to obtain permission directly from the copyright holder. To view a copy of this license, visit http://creativecommons.org/ licenses/by/4.0/.
}

(c) The Author(s) 2021 